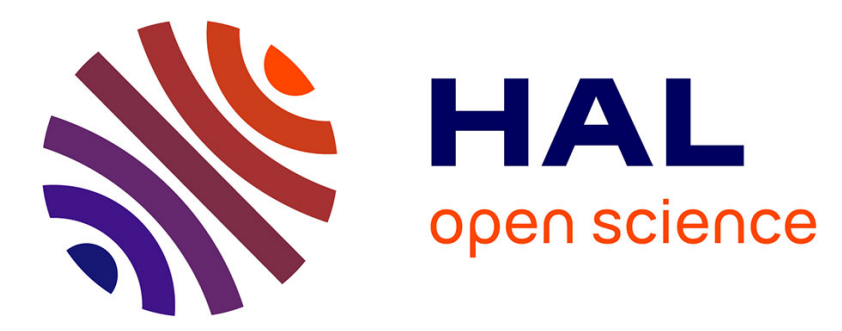

\title{
Thermal Dehydration of Lithium Sulfate Monohydrate Revisited with Universal Kinetic Description over Different Temperatures and Atmospheric Water Vapor Pressures
}

\author{
Yui Yamamoto, Loïc Favergeon, Nobuyoshi Koga
}

\section{To cite this version:}

Yui Yamamoto, Loïc Favergeon, Nobuyoshi Koga. Thermal Dehydration of Lithium Sulfate Monohydrate Revisited with Universal Kinetic Description over Different Temperatures and Atmospheric Water Vapor Pressures. Journal of Physical Chemistry C, 2020, 124 (22), pp.11960 - 11976. 10.1021/acs.jpcc.0c02739 . emse-02973065

\section{HAL Id: emse-02973065 \\ https://hal-emse.ccsd.cnrs.fr/emse-02973065}

Submitted on 22 Oct 2020

HAL is a multi-disciplinary open access archive for the deposit and dissemination of scientific research documents, whether they are published or not. The documents may come from teaching and research institutions in France or abroad, or from public or private research centers.
L'archive ouverte pluridisciplinaire HAL, est destinée au dépôt et à la diffusion de documents scientifiques de niveau recherche, publiés ou non, émanant des établissements d'enseignement et de recherche français ou étrangers, des laboratoires publics ou privés. 


\title{
Thermal Dehydration of Lithium Sulfate Monohydrate Revisited with Universal Kinetic Description over Different Temperatures and Atmospheric Water Vapor Pressures
}

Yui Yamamoto, ${ }^{a}$ Loic Favergeon, ${ }^{\mathrm{b}}$ and Nobuyoshi Koga ${ }^{{ }^{* a}}$

${ }^{a}$ Chemistry Laboratory, Department of Science Education, Graduate School of Education, Hiroshima University, 11-1 Kagamiyama, Higashi-Hiroshima 739-8524, Japan.

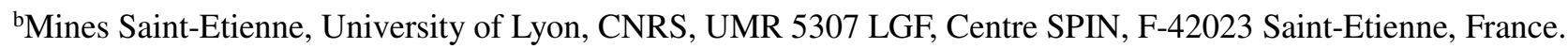

\begin{abstract}
This study aims to universally describe the kinetic features of the thermal dehydration of lithium sulfate monohydrate across different temperatures $(T)$ and atmospheric water vapor pressures $\left(p\left(\mathrm{H}_{2} \mathrm{O}\right)\right)$, as a model reaction of the thermal dehydration of crystalline hydrates. Initially, the features of the physico-geometrical consecutive process, comprising the induction period (IP)-surface reaction (SR)-phase boundary-controlled reaction (PBR), were revealed by tracking the mass-loss behavior during thermal dehydration under various heating and atmospheric conditions, as well as through microscopic observation of the reaction particles. Then, the accommodation function (AF), accounting for the effect of $p\left(\mathrm{H}_{2} \mathrm{O}\right)$ on the kinetic behavior, was derived based on classical solid-state reaction theories. The modified kinetic equation with the AF was successfully applied to both the IP and mass-loss process through Arrhenius-type and isoconversional kinetic calculations, respectively, realizing the universal kinetic approach. Furthermore, on the basis of the IP-SR-PBR $(n)$ model, kinetic information on the respective reaction steps was obtained from isothermal kinetic curves recorded at each $T$ and $p\left(\mathrm{H}_{2} \mathrm{O}\right)$ value. Finally, the universal kinetic descriptions for each physico-geometrical reaction step were obtained using the modified kinetic equation with the AF. The kinetic features were revealed by comparing the magnitude relations of the resultant kinetic parameters in each reaction step and investigating the variations of each kinetic parameter as the reaction step advanced. The significance of the proposed universal kinetic approach was discussed to gain further insight into the nature of the thermal dehydration of crystalline hydrates.
\end{abstract}

Keywords:

Kinetics; Thermal dehydration; Kinetics; Lithium sulfate monohydrate; Atmospheric water vapor; Accommodation function 


\section{Introduction}

The thermal dehydration of inorganic crystalline hydrates has been studied to reveal various specific features of solid-state reactions, as well as the solid-gas system. The kinetic behavior has been extensively investigated in relation to (i) the topochemical constraints of the reaction geometry, (ii) the nucleation and interface reaction kinetics, and (iii) the effect of intensive parameters on reaction kinetics. ${ }^{1-5}$ The outcomes of these studies have contributed to the establishment of the widely recognized theory of solid-state reaction kinetics, which considers changes in the reaction rate as the reaction advances and depending on temperature $(T)$. The most fundamental kinetic is expressed as an equation in differential form by using the physico-geometrical kinetic model function $f(\alpha)$ and assuming Arrhenius-type temperature dependence: ${ }^{6-8}$

$$
\frac{\mathrm{d} \alpha}{\mathrm{d} t}=A \exp \left(-\frac{E_{\mathrm{a}}}{R T}\right) f(\alpha)
$$

where $\alpha$ is the fractional reaction defined by the conversion ratio at time $t$ with reference to the total conversion value during the reaction. $E_{\mathrm{a}}, A$, and $R$ are the apparent activation energy, Arrhenius preexponential factor, and gas constant, respectively. Advancement of the kinetic theory was promoted by the development of various techniques that reveal the characteristics of the process in further detail and track the process to obtain more precise kinetic data and advancement of the mathematical processing technology. Thermal analysis has been used as a powerful technique, and its advancement has provided the opportunity to improve the procedures of kinetic analysis, including kinetic data measurement, kinetic calculation, and consequently, kinetic theory. At each stage of the technological innovation, the kinetic study of the thermal dehydration of crystalline hydrates has been repeated for establishing up-to-date theory and improving the kinetic analysis procedures of the solid-state reaction.

Thermal dehydration of lithium sulfate monohydrate (LSM) is one such crystalline hydrate studied extensively as a model reaction:

$$
\mathrm{Li}_{2} \mathrm{SO}_{4} \cdot \mathrm{H}_{2} \mathrm{O}(\mathrm{s}) \rightleftarrows \mathrm{Li}_{2} \mathrm{SO}_{4}(\mathrm{~s})+\mathrm{H}_{2} \mathrm{O}(\mathrm{g})
$$

In the early 1990s, i.e., at the time when the thermoanalytical instruments were becoming fully equipped with personal computer, much research was dedicated to the kinetic study of this reaction. This was in response to a proposal from the kinetic committee of the International Confederation for Thermal Analysis and Calorimetry (ICTAC; chairman: J.H. Flynn at that time) for establishing the standard procedures for kinetic analysis using thermoanalytical techniques. ${ }^{9}$ With reference to the previously reported kinetic studies for the reaction (Okhotnikov et al., ${ }^{10-13}$ Koga and Tanaka, ${ }^{14-15}$ and Galwey et al., ${ }^{16}$ ), variously oriented kinetic studies were conducted using different techniques under different sample and measurement conditions, including differing sample characteristics, sample masses, atmospheres, and heating conditions, ${ }^{17-26}$ in which the kinetic results obtained using different kinetic calculation methods were also compared. The major kinetic results reported during that period are summarized in Section $\mathrm{S} 1$ in the ESI. The reported kinetic parameters were widely distributed, with the $E_{\mathrm{a}}$ values ranging from 22 to $272 \mathrm{~kJ} \mathrm{~mol}^{-1}$ depending on the experimental and calculational variabilities, that was accompanied by a compensative change in the $A$ value, yielding a linear correlation between $\ln A$ and $E_{\mathrm{a}}$ values, known as the kinetic compensation effect, ${ }^{27-34}$ as shown in Figure S1. Although the results exposed many problems related to the reliable kinetic analysis of solid-state reactions, various kinetic features of the reaction were identified, making the reaction in Eq. (2) a target for further kinetic studies as a model reaction.

Two differently oriented studies of the reaction have been more recently performed based on the results of the work conducted in the early 1990s. One originated from microscopic studies of the surface reaction (SR) and 
the subsequent phase boundary-controlled reaction (PBR), as well as the estimated $f(\alpha)$, through formal kinetic analysis. Clear evidence of the physico-geometrical consecutive process, comprising SR and subsequent PBR, have been shown through microscopic observations. ${ }^{15-16,35-36}$ In the formal kinetic analysis of a single-crystal sample, the two or three-dimensional PBR has been estimated; whereas, for powder samples, the nucleation and growth model of Johnson-Mehl-Avrami (JMA $(m))^{37-40}$ was empirically selected in many previous studies based on the best fitting procedures regardless of the discrepancy between the actual reaction mechanism and the physico-geometrical basis of the JMA $(m)$ model. The kinetic modeling of the reaction of powder samples as the physico-geometrical consecutive SR-PBR process was initially performed by Valdivieso et al. ${ }^{41}$ This study was further extended to single-crystal samples by Favergeon et al., ${ }^{42-43}$ focusing on the applicability of SR-PBR model and kinetics of induction period (IP) and surface nucleation. The kinetic modeling of the physico-geometrical consecutive SR-PBR process, originally proposed by Mampel, ${ }^{44}$ was later reformulated as the nucleation and anisotropic growth model by Favergeon et al., ${ }^{45}$ and the simplified differential kinetic equations for the consecutive IP-SR-PBR process were derived by Ogasawara and Koga ${ }^{46}$ for practical kinetic calculation. Similar physico-geometrical kinetic modeling of the reaction was demonstrated recently by Lan et al. ${ }^{47-48}$ based on the detailed optical microscopic measurements of surface nucleation, surface growth, and bulk growth processes.

The other kinetic approach to the reaction concerns the effect of water vapor pressure $\left(p\left(\mathrm{H}_{2} \mathrm{O}\right)\right)$, which is the gaseous product of the reaction. The retardation effect of $p\left(\mathrm{H}_{2} \mathrm{O}\right)$ on the overall reaction rate was reported by Huang and Gallagher. ${ }^{18}$ The effect of $p\left(\mathrm{H}_{2} \mathrm{O}\right)$ on the kinetic behavior at a selected temperature at $353 \mathrm{~K}$ was discussed by Valdivieso et al. ${ }^{41}$ in connection with the kinetic modeling of the sigmoidal mass-loss curves. Seto et al. ${ }^{49}$ reported the kinetic behavior under isothermal conditions at different temperatures and at different $p\left(\mathrm{H}_{2} \mathrm{O}\right)$ values ranging from 0 to $2.7 \mathrm{kPa}$. Besides the hinderance effect of $p\left(\mathrm{H}_{2} \mathrm{O}\right)$ on the reaction rate above $1 \mathrm{kPa}$, the unusual behavior of an initial decrease and subsequent increase in the rate constant with increasing $p\left(\mathrm{H}_{2} \mathrm{O}\right)$ was observed at $p\left(\mathrm{H}_{2} \mathrm{O}\right)$ values lower than $1 \mathrm{kPa}$, which is known as the Smith-Topley effect. ${ }^{50-52}$ Favergeon and Pijolat ${ }^{53}$ investigated the effect of $p\left(\mathrm{H}_{2} \mathrm{O}\right)$ on the IP for the thermal dehydration of single crystals, observing prolongation of the IP duration time with increasing $p\left(\mathrm{H}_{2} \mathrm{O}\right)$ values at a selected temperature of $353 \mathrm{~K}$. The effect of $p\left(\mathrm{H}_{2} \mathrm{O}\right)$ on the reaction rate and the possible cause of the Smith-Topley effect were discussed by L'vov et al. ${ }^{54}$ using an alternative kinetic modeling based on a model of dissociative evaporation of the reactant solid, followed by the condensation of the solid product. ${ }^{55} \mathrm{An}$ interesting experimental approach for revealing the thermal dehydration kinetics during continuous cooling was recently reported by Liavitskaya and Vyazovkin, ${ }^{56-57}$ where a systematic decrease in the isoconversional $E_{\mathrm{a}}$ value as the reaction advanced was observed for the reaction during cooling, as reported previously in many articles for the reaction during heating. ${ }^{15,18-19,22}$ The cause of variation in the isoconversional $E_{\mathrm{a}}$ value was discussed in connection with the effect of the self-generated $p\left(\mathrm{H}_{2} \mathrm{O}\right)$.

Further advanced kinetic approach to the thermal dehydration of LSM can be attempted by integrating the kinetic behavior information of the thermal dehydration of LSM, focusing on the physico-geometrical reaction mechanism and the effect of $p\left(\mathrm{H}_{2} \mathrm{O}\right)$. A universal kinetic description of the reaction over different temperature and $p\left(\mathrm{H}_{2} \mathrm{O}\right)$ conditions is required to reveal the relation between the reaction kinetics and the reaction equilibrium. Furthermore, by introducing kinetic modeling of the physico-geometrical consecutive process, kinetics of each physico-geometrical reaction step can be described as a function of $T$ and $p\left(\mathrm{H}_{2} \mathrm{O}\right)$, which enable the evaluation of changes in the kinetics as the reaction step advances and compare the kinetic characteristics with a comparable 
series of reactions using kinetic parameters describing $T$ and $p\left(\mathrm{H}_{2} \mathrm{O}\right)$ dependences. The success of the universal kinetic description over different temperature and $p\left(\mathrm{H}_{2} \mathrm{O}\right)$ conditions based on the physico-geometrical consecutive reaction model is expected to bring the kinetic understanding of the thermal dehydration and decomposition to with a new level by categorizing the kinetic behavior with reference to the magnitude relation between the kinetic parameters and their variation as the reaction step advances. Recently, we have succeeded in providing the desired universal kinetic description for a series of thermal decompositions of metal hydroxides. ${ }^{58-59}$ The present study aims to provide the universal kinetic description in each physico-geometrical reaction step for the well-studied model reaction of the thermal dehydration of LSM, as a necessary step toward reaching a new level of kinetic understanding.

\section{Experimental section}

\subsection{Sample preparation and characterization}

Single crystals with a long axis length in the range from 1.0 to $2.0 \mathrm{~mm}$ (Figure S2) were grown from a supersaturated solution of an LSM reagent (special grade, $>99.0 \%$, Katayama Chem. Ind.). The single crystals of desired size were collected from the supersaturated solution and dried in air. The sample was characterized as $\mathrm{Li}_{2} \mathrm{SO}_{4} \cdot \mathrm{H}_{2} \mathrm{O}$ via powder X-ray diffractometry (XRD) (Figure S3), Fourier transform infrared spectroscopy (FT-IR) (Figure S4), and thermogravimetry (TG)-differential thermal analysis (DTA) (Figure S5) before being subjected to the thermoanalytical measurements described below. Changes in the XRD patterns of the sample during heating were traced by high-temperature XRD measurements (Figure S6) and the dehydration product was identified as $\mathrm{Li}_{2} \mathrm{SO}_{4}$. Section S2 in the ESI details the sample characterization.

\subsection{Thermoanalytical measurements}

Approximately $5.0 \mathrm{mg}$ of the single crystals (5-6 particles) were weighed into a platinum sample pan (5 $\mathrm{mm}$ in diameter and $2.5 \mathrm{~mm}$ in height), whose inner-bottom surface was pre-lined with a small amount of glass wool (approximately $0.5 \mathrm{mg}$ ) to allow exposure of all surfaces of the sample particles by preventing contact between the single crystals and the surface of the pan and other single crystals. The sample was loaded onto a TG-DTA instrument (TG-8121, Thermoplus Evo2, Rigaku). The thermal dehydration process was traced in flowing $\mathrm{N}_{2}$ gas at a flowrate of $300 \mathrm{~cm}^{3} \mathrm{~min}^{-1}$. The water vapor pressure of the outlet gas was monitored using a hygrometer (HUHBN-HT20E, NGK Spark Plug Co.) and determined to be $0.26 \mathrm{kPa}$. The sample was heated according to three different temperature program modes including isothermal, linear nonisothermal, and controlled transformation rate thermal analysis (CRTA ${ }^{60-61}$ conditions. For the isothermal measurements, the sample was heated at a heating rate, $\beta$, of $10 \mathrm{~K} \mathrm{~min}^{-1}$ to a predetermined temperature in the range $348-372 \mathrm{~K}$, which was maintained during recording of the mass-loss curve. The TG-DTA curves under liner nonisothermal conditions were recorded upon heating from room temperature to $523 \mathrm{~K}$ at different $\beta$ values ranging from 0.5 to $10 \mathrm{~K} \mathrm{~min}^{-1}$. The CRTA measurements were conducted with a linear nonisothermal program at $\beta=2 \mathrm{~K} \mathrm{~min}^{-1}$, whereas during the mass-loss process, the massloss rate, $C$, was controlled at different program values in the range $2.5-25 \mu \mathrm{g} \mathrm{min}{ }^{-1}$.

For tracking the mass-loss process during the thermal dehydration of LSM at higher controlled $p\left(\mathrm{H}_{2} \mathrm{O}\right)$ values, a humidity-controlled TG-DTA system (TG-8120, Thermoplus 2, Rigaku) ${ }^{62}$ equipped with a humidity controller (HUM-1, Rigaku) for the inflow $\mathrm{N}_{2}$ gas was used. The flowrate of $\mathrm{N}_{2}$ gas was varied in a range 350-400 $\mathrm{cm}^{3} \mathrm{~min}^{-1}$ depending on the controlled $p\left(\mathrm{H}_{2} \mathrm{O}\right)$ value during the TG-DTA measurements. After the sample 
(approximately $5.0 \mathrm{mg}$ ) was weighed in the platinum pan with procedure described above and loaded on the instrument, the TG-DTA run was started by flowing dry $\mathrm{N}_{2}$ gas to heat the sample to $323 \mathrm{~K}$ at $\beta=5 \mathrm{~K} \mathrm{~min}^{-1}$. Then, the gas flow was switched to wet $\mathrm{N}_{2}$ gas with a certain controlled $p\left(\mathrm{H}_{2} \mathrm{O}\right)$ value, and the sample temperature was maintained at $323 \mathrm{~K}$ for $30 \mathrm{~min}$ to establish the atmospheric conditions. Thereafter, the TG-DTG curves were recorded by heating the sample under linear nonisothermal and isothermal conditions. The effect of the atmospheric $p\left(\mathrm{H}_{2} \mathrm{O}\right)$ value on the mass-loss process under a linear nonisothermal condition at $\beta=5 \mathrm{~K} \mathrm{~min}^{-1}$ was examined through the measurements under different controlled atmospheric $p\left(\mathrm{H}_{2} \mathrm{O}\right)$ values in the range $0.8-9.1 \mathrm{kPa}$. The mass-loss curves used for the kinetic calculations were collected at three different controlled $p\left(\mathrm{H}_{2} \mathrm{O}\right)$ values, i.e., $0.8,3.7$, and $8.7 \mathrm{kPa}$. Under each $p\left(\mathrm{H}_{2} \mathrm{O}\right)$ condition, the mass-loss curves at different constant temperatures were initially recorded by heating the sample from $323 \mathrm{~K}$ to a programmed temperature at $\beta=5 \mathrm{~K} \mathrm{~min}^{-1}$ and maintaining the temperature until the mass-loss process was complete. The temperature range of the isothermal measurements was forced to change depending on the atmospheric $p\left(\mathrm{H}_{2} \mathrm{O}\right)$ value, and the available temperature width of the series of isothermal measurements at each controlled $p\left(\mathrm{H}_{2} \mathrm{O}\right)$ value narrowed with increasing $p\left(\mathrm{H}_{2} \mathrm{O}\right)$ value. A temperature width of $12 \mathrm{~K}$ was ensured for the series at the highest controlled $p\left(\mathrm{H}_{2} \mathrm{O}\right)$ value, i.e., $8.71 \mathrm{kPa}$. Similarly, a series of mass-loss curves under linear nonisothermal conditions were collected at different $\beta$ values in the range $1-10 \mathrm{~K}$ $\min ^{-1}$. The average mass-loss value across all mass-loss curves under different heating and $p\left(\mathrm{H}_{2} \mathrm{O}\right)$ conditions was $13.97 \pm 0.57 \%$, which corresponds to the calculated value according to Eq. (2), i.e., $14.08 \%$. The instrumental setup for the measurements is detailed in Section S3 in the ESI.

The appearance of the sample in the platinum pan was continuously recorded during the TG-DTA measurement under isothermal condition $(T=344 \mathrm{~K})$ in flowing $\mathrm{N}_{2}$ gas (flowrate: $300 \mathrm{~cm}^{3} \mathrm{~min}^{-1} ; p\left(\mathrm{H}_{2} \mathrm{O}\right): 0.26$ $\mathrm{kPa}$ ) using a TG-DTA instrument (TG-8121, Thermoplus Evo2, Rigaku) equipped with a digital video camera (SKM-S20C-PC-R, Saitoh Kogaku). Changes in the surface texture of the sample during isothermal heating of the sample in the heating stage (STJ-M100-01P-HU-SP, S.T.J) at $351 \mathrm{~K}$ in flowing $\mathrm{N}_{2}$ gas (flowrate: $100 \mathrm{~cm}^{3} \mathrm{~min}^{-1}$, $p\left(\mathrm{H}_{2} \mathrm{O}\right): 0.26 \mathrm{kPa}$ ) were observed using an optical microscope (BH-2, Olympus).

\section{Results and Discussion}

\subsection{Effect of water vapor on thermal behavior}

Figure 1 compares the TG-derivative TG (DTG) curves for the thermal dehydration of LSM recorded under different $p\left(\mathrm{H}_{2} \mathrm{O}\right)$ values at the same constant temperature, i.e., $373 \mathrm{~K}$. The appearance of a distinguishable IP under isothermal conditions is observed irrespective of the $p\left(\mathrm{H}_{2} \mathrm{O}\right)$ values. The IP duration time, $t_{\mathrm{IP}}$, is significantly prolonged as the $p\left(\mathrm{H}_{2} \mathrm{O}\right)$ value increases, as reported by Favergeon et al..$^{53}$ The mass-loss process during the thermal dehydration under isothermal conditions is characterized by a sigmoidal shape with the maximum mass-loss rate midway through the reaction. The mass-loss rate is retarded by the effect of the atmospheric $p\left(\mathrm{H}_{2} \mathrm{O}\right)$ value. This behavior is also observed for the TG-DTG curve recorded under different $p\left(\mathrm{H}_{2} \mathrm{O}\right)$ values during nonisothermal heating at a fixed $\beta$ value, as shown in Figure 2. The TG-DTG curves systematically shift to higher temperatures with increasing atmospheric $p\left(\mathrm{H}_{2} \mathrm{O}\right)$ values (Figure 2(a)). The shape of the DTG curves also changes with the $p\left(\mathrm{H}_{2} \mathrm{O}\right)$ values, as characterized by the decrease in the temperature interval between the extrapolated onset $\left(T_{\text {eo }}\right)$ and peak top $\left(T_{\mathrm{p}}\right)$ temperatures and increase in the DTG peak height (Figure 2(b)). The TG-DTG curves recorded at the highest $p\left(\mathrm{H}_{2} \mathrm{O}\right)$ value do not necessarily follow this trend. This is due to the self-cooling effect, which concaves the 
programmed linear heating of the sample. Within the temperature and $p\left(\mathrm{H}_{2} \mathrm{O}\right)$ conditions examined in this study, the inversion phenomena in the relation between the reaction rate and $p\left(\mathrm{H}_{2} \mathrm{O}\right)$, as described by the Smith-Topley behavior, cannot be observed.

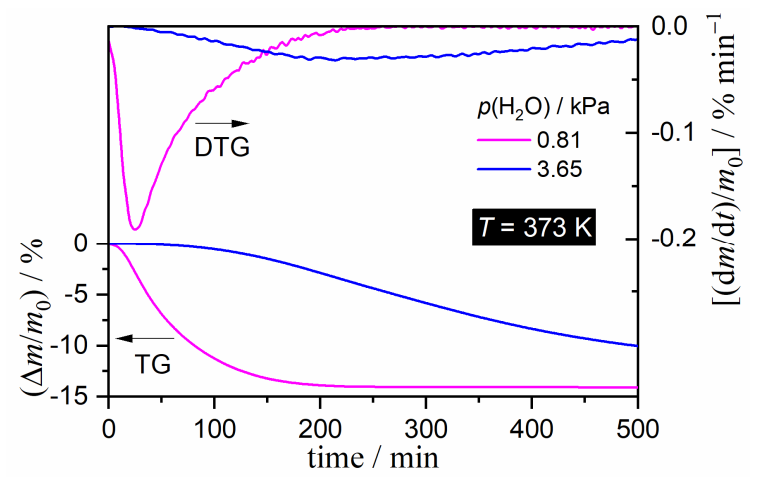

Figure 1. Comparison of isothermal mass-loss curves for the thermal dehydration of LSM as recorded at a constant temperature of $373 \mathrm{~K}$ in flowing wet $\mathrm{N}_{2}$ gas with different controlled $p\left(\mathrm{H}_{2} \mathrm{O}\right)$ values, i.e., 0.81 and $3.65 \mathrm{kPa} .\left(m_{0}=\right.$ 5.723 and $4.919 \mathrm{mg}$ for the measurements at $p\left(\mathrm{H}_{2} \mathrm{O}\right)=0.81$ and $3.65 \mathrm{kPa}$, respectively.)
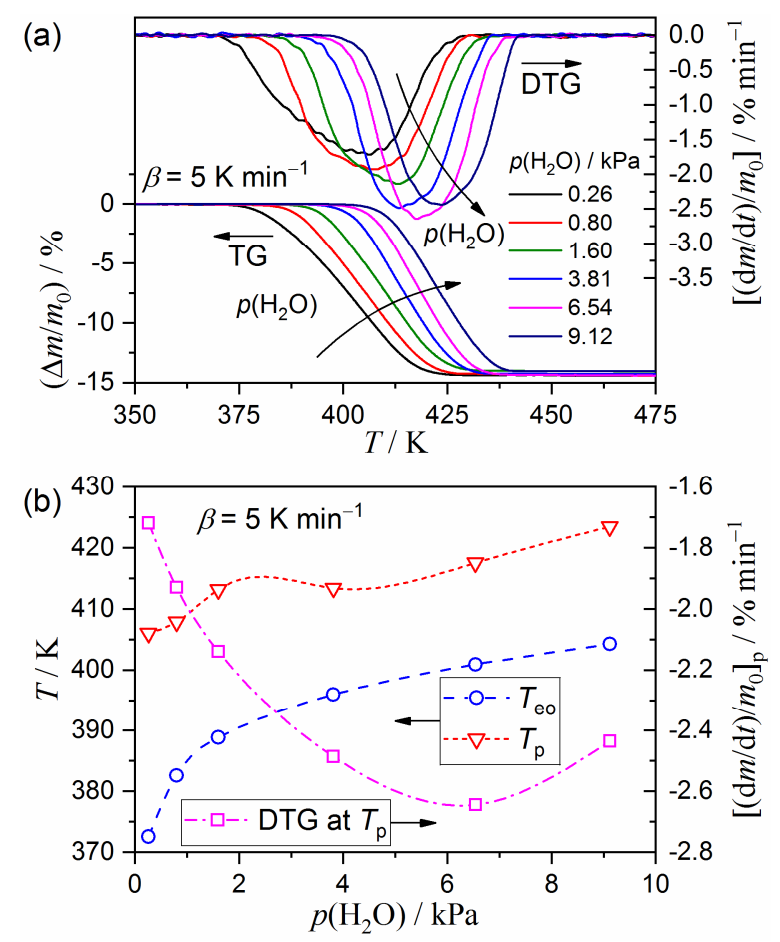

Figure 2. Effect of $p\left(\mathrm{H}_{2} \mathrm{O}\right)$ value on the mass-loss curves for the thermal dehydration of LSM $\left(m_{0}=5.520 \pm 0.378\right.$ $\mathrm{mg}$ ) as recorded under linear nonisothermal conditions at $\beta=5 \mathrm{~K} \mathrm{~min}^{-1}$ in flowing wet $\mathrm{N}_{2}$ gas. (a) TG-DTG curves and (b) changes in $T_{\mathrm{eo}}, T_{\mathrm{p}}$, and the maximum height of the DTG peak.

Figure 3 shows the changes in the appearance of the sample crystals during TG-DTG measurement at a constant temperature ( $344 \mathrm{~K}$ ) in flowing $\mathrm{N}_{2}$ gas (flowrate: $300 \mathrm{~cm}^{3} \mathrm{~min}^{-1}, p\left(\mathrm{H}_{2} \mathrm{O}\right)=0.26 \mathrm{kPa}$ ). During the IP, no distinguishable change in the surface texture of the sample particles is observed (A-D). As soon as the mass loss is detected, several regions of the surfaces of the selected sample particles start becoming clouded through the 
formation of a solid product (E). Subsequently, the clouded regions increase in the manner of nucleation and growth $(\mathrm{F}, \mathrm{G})$, and all of the surfaces are covered by the solid product at a mass-loss ratio of approximately $2.7 \%(\mathrm{H})$, which corresponds to the fractional reaction of $\alpha=0.19$. During the surface reaction, the preliminarily clouded regions gradually turn white and devitrify. This observation implies that the reaction interfaces formed by the surface reaction successively advance toward the center of the reactant particles. At the same time, there are detectable distributions of the fractional reaction between the reactant particles. After the surfaces of all reactant particles are covered by the surface product layer, no distinguishable change in the particle appearance is observed during the second half of the mass-loss process $(\mathrm{H}-\mathrm{J})$. The advancement of the reaction interface toward the center of each reacting particle is the predominant process during the second half of the mass-loss process. Figure 4 shows the changes in the microscopic views of a selected crystal surface during the isothermal heating at $351 \mathrm{~K}_{\text {in }}$ flowing $\mathrm{N}_{2}$ gas (flowrate: $100 \mathrm{~cm}^{3} \mathrm{~min}^{-1}, p\left(\mathrm{H}_{2} \mathrm{O}\right)=0.26 \mathrm{kPa}$ ). Although no distinguishable change in the surface texture is observed during the IP ( $a$ and $b$ ), the IP duration time is variable for the single crystalline particles in the sample matrix. The reaction is initiated by random nucleation on the surface and subsequent growth covers the reactant surfaces with the solid product (c-f). These observations suggest that the IP duration represents the preparation time before initiating the mass-loss process, which is initiated by the surface reaction. The subsequent mass loss is a result of movement of the as-produced reaction interface between the surface product layer and the internal reactant crystal toward the particle centers. The physico-geometrical reaction mechanisms, as deduced from the morphological observations, are perfectly in accordance with the previously reported mechanisms. ${ }^{15-16,42,47-48,53}$
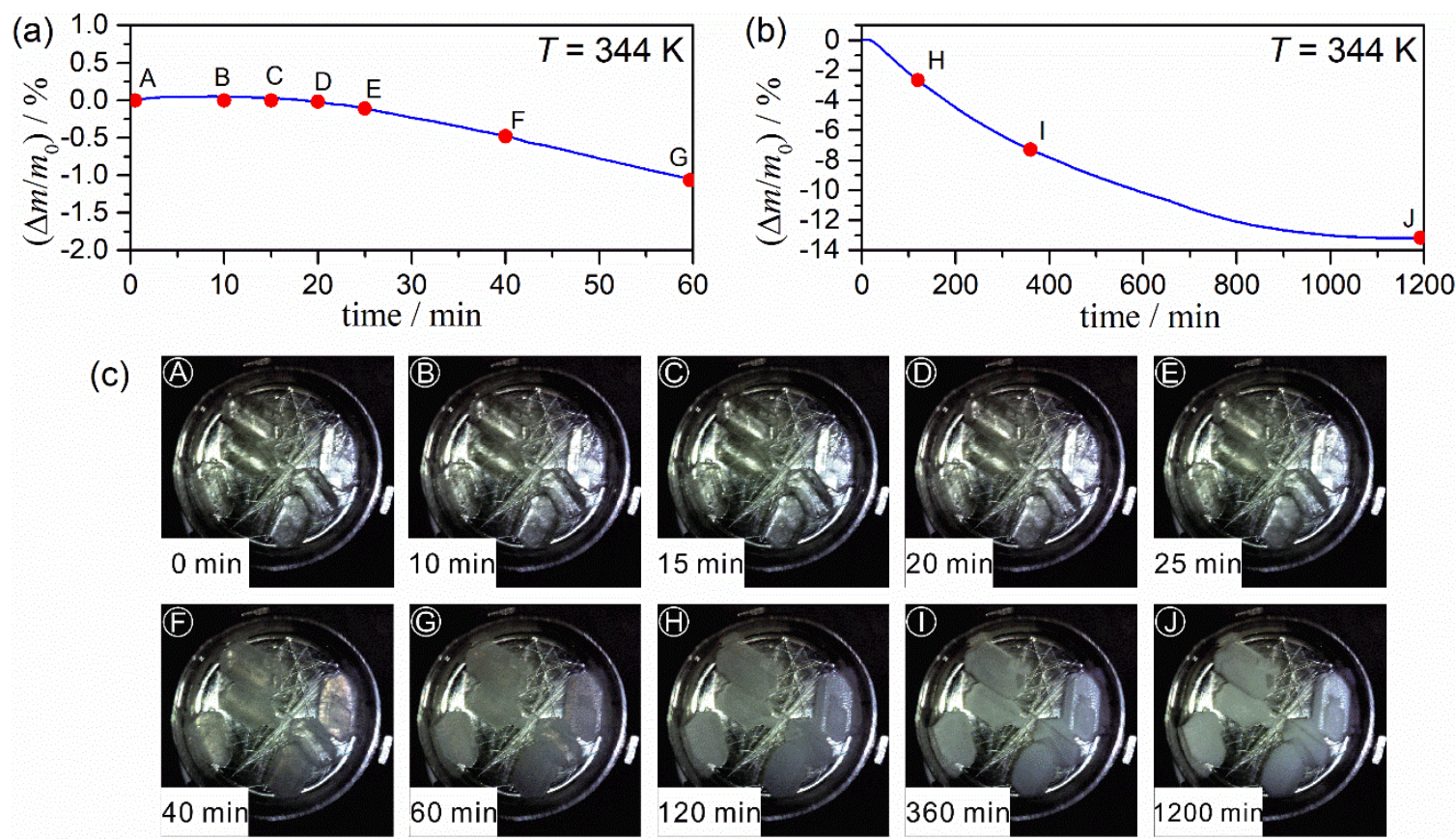

Figure 3. Changes in the appearance of the reactant particles during the measurement of mass-loss curves for the thermal dehydration of LSM $\left(m_{0}=4.815 \mathrm{mg}\right)$ at a constant temperature of $344 \mathrm{~K}$ in flowing $\mathrm{N}_{2} \operatorname{gas}\left(p\left(\mathrm{H}_{2} \mathrm{O}\right)=0.26\right.$ $\mathrm{kPa}$ ): (a) mass-loss curve in the initial part of the reaction, (b) mass-loss curve during the overall reaction, and (c) appearance of the sample particles at various reaction times suggested in the mass-loss curves in (a) and (b). 

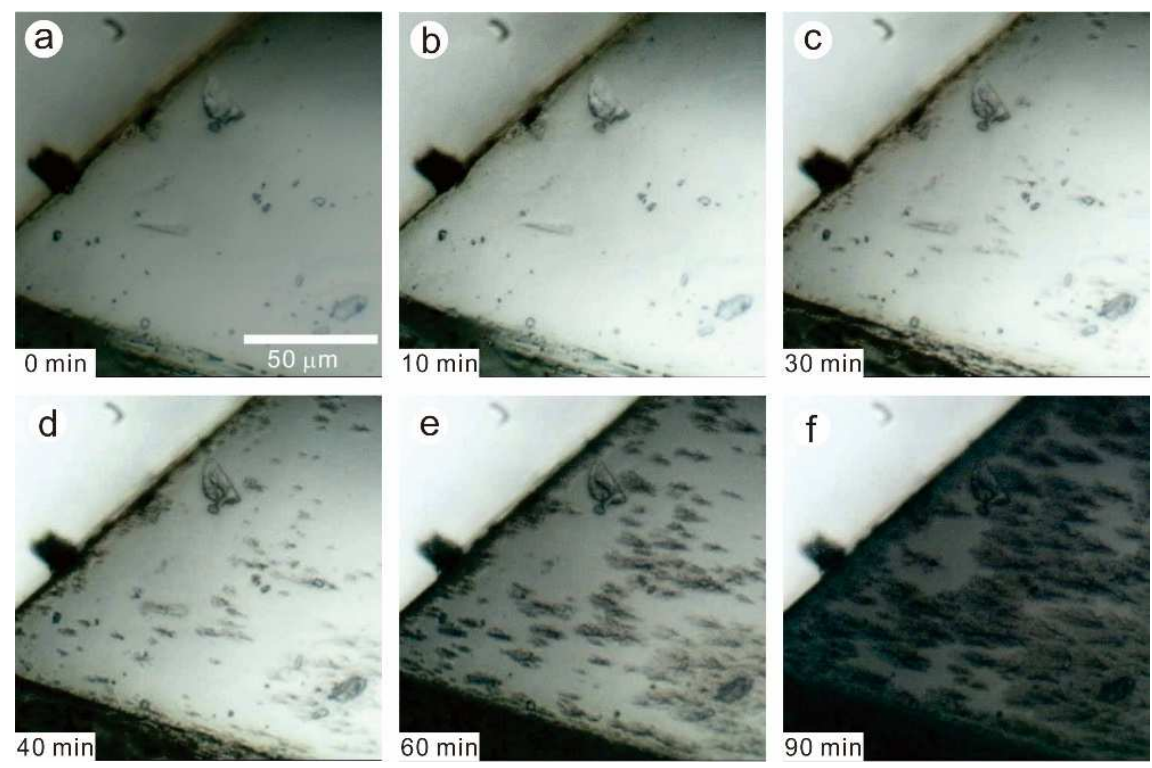

Figure 4. Changes in the microscopic views of a selected surface of an LSM crystal during heating at $351 \mathrm{~K}$ in flowing $\mathrm{N}_{2}$ gas $\left(p\left(\mathrm{H}_{2} \mathrm{O}\right)=0.26 \mathrm{kPa}\right)$.

\subsection{Induction period}

Figure 5 shows the mass-loss curves for the thermal dehydration of LSM recorded at various constant temperatures under flowing wet $\mathrm{N}_{2}$ gas with different controlled $p\left(\mathrm{H}_{2} \mathrm{O}\right)$ values, i.e., $0.26,0.81,3.65$, and $8.63 \mathrm{kPa}$. At each $p\left(\mathrm{H}_{2} \mathrm{O}\right)$ value, the mass-loss curves transform with temperature, indicating that the mass-loss rate increases with temperature in an ordinal manner. By comparing the mass-loss curves recorded under different $p\left(\mathrm{H}_{2} \mathrm{O}\right)$ values, prolongation of the IP and the retardation of the mass-loss rate at a given temperature are observed with increasing $p\left(\mathrm{H}_{2} \mathrm{O}\right)$ values. Because of this behavior, it is necessary to shift the measurement temperature range of the isothermal mass-loss curves to higher temperatures at increasing $p\left(\mathrm{H}_{2} \mathrm{O}\right)$ values.
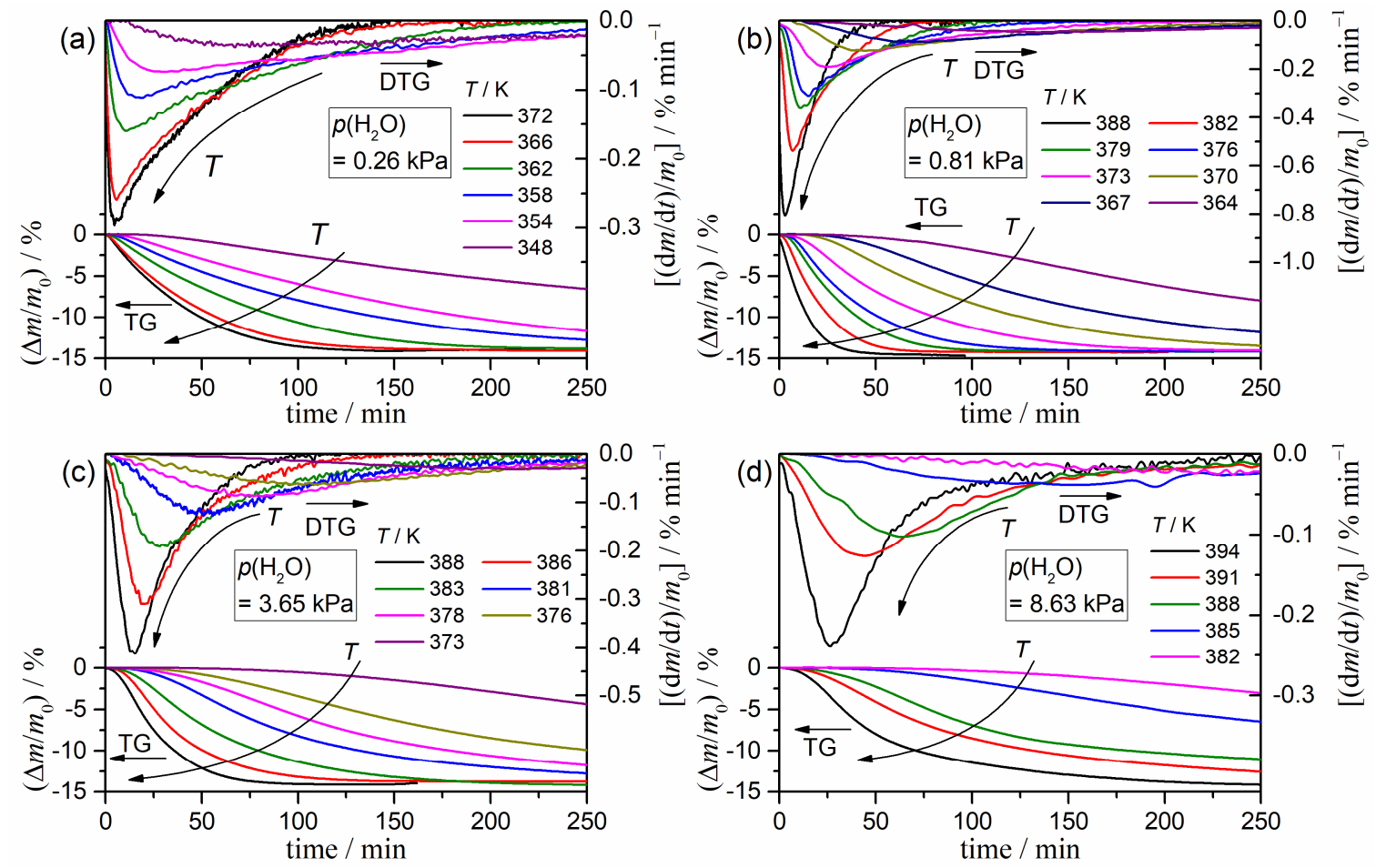
Figure 5. Mass-loss curves for the thermal dehydration of LSM recorded at different temperatures in flowing wet $\mathrm{N}_{2}$ gas with different controlled $p\left(\mathrm{H}_{2} \mathrm{O}\right)$ values: (a) $0.26 \mathrm{kPa}\left(m_{0}=5.403 \pm 0.301 \mathrm{mg}\right)$, (b) $0.81 \mathrm{kPa}\left(m_{0}=5.315 \pm\right.$ $0.313 \mathrm{mg})$, (c) $3.65 \mathrm{kPa}\left(m_{0}=5.227 \pm 0.220 \mathrm{mg}\right)$, and (d) $8.63 \mathrm{kPa}\left(m_{0}=5.222 \pm 0.292 \mathrm{mg}\right)$.

The $t_{\mathrm{IP}}$ value is determined for each mass-loss curve using empirical definitions of the zero time and the end time of the IP; the zero time is defined as that at which the sample temperature reaches the programmed temperature, whereas the end time of the IP is defined as that at which the mass-loss value reaches $0.15 \%(\alpha=0.01$ for the mass-loss process). Figure 6 shows the changes in the $t_{\mathrm{IP}}$ values with temperature and $p\left(\mathrm{H}_{2} \mathrm{O}\right)$ value. The $t_{\mathrm{IP}}$ value at each $p\left(\mathrm{H}_{2} \mathrm{O}\right)$ value increases exponentially with decreasing temperature. The temperature versus $t_{\mathrm{IP}}$ curves shift systematically to higher temperatures with increasing $p\left(\mathrm{H}_{2} \mathrm{O}\right)$ values. The reciprocal of $t_{\mathrm{IP}}$ can be interpreted as the average rate of the physico-chemical process that occurs during the IP. Therefore, an Arrhenius-type relation is expected between the reciprocal $t_{\mathrm{IP}}$ and absolute temperature $T .46,63-68$

$$
\frac{1}{t_{\mathrm{IP}}}=A_{\mathrm{IP}} \exp \left(-\frac{E_{\mathrm{a}, \mathrm{IP}}}{R T}\right) f\left(\alpha_{\mathrm{IP}}\right)
$$

where $A_{\mathrm{IP}}, E_{\mathrm{a}, \mathrm{IP}}, \alpha_{\mathrm{IP}}$, and $f\left(\alpha_{\mathrm{IP}}\right)$ are the apparent preexponential factor, apparent activation energy, fractional conversion, and conversion function, respectively, for the IP, and $R$ is the gas constant. Figure $\mathrm{S} 9$ shows the Arrhenius plots for the IP at each $p\left(\mathrm{H}_{2} \mathrm{O}\right)$ value. The Arrhenius plots exhibit different linear correlations for the IP processes at different $p\left(\mathrm{H}_{2} \mathrm{O}\right)$ values, although each Arrhenius plot at a selected $p\left(\mathrm{H}_{2} \mathrm{O}\right)$ value is characterized by a statistically significant linear correction, with correlation coefficients greater than -0.9771 , even in the worst case. The slope of the Arrhenius plots increases with the $p\left(\mathrm{H}_{2} \mathrm{O}\right)$ value, resulting in increases in the apparent $E_{\mathrm{a}, \mathrm{IP}}$ and $\ln$ $\left[A_{\mathrm{IP}} f\left(\alpha_{\mathrm{IP}}\right)\right]$ values, as listed in Table $\mathrm{S} 2$. The results indicate that the systematic changes in the kinetic behavior of the IP with the $p\left(\mathrm{H}_{2} \mathrm{O}\right)$ value should be incorporated into the kinetic description.

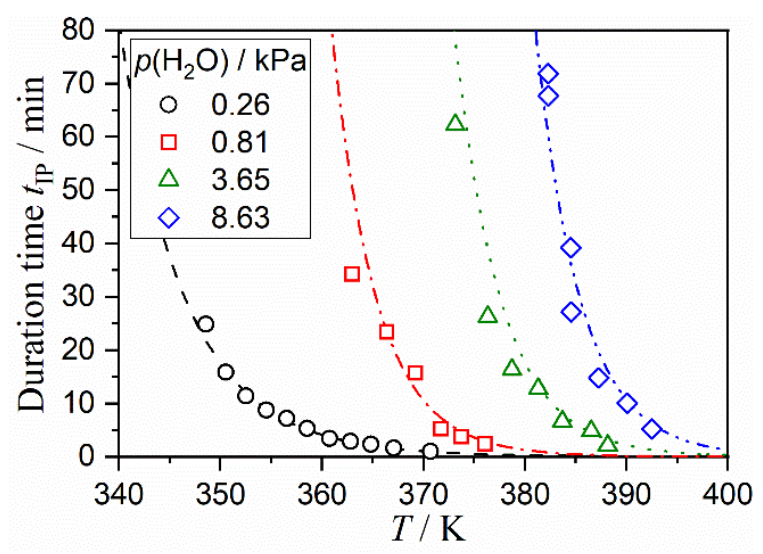

Figure 6. Changes in $t_{\mathrm{IP}}$ values for the thermal dehydration of LSM with temperature and $p\left(\mathrm{H}_{2} \mathrm{O}\right)$ values. Lines are drawn by assuming the Arrhenius-type temperature dependence for each series of data points at a specific $p\left(\mathrm{H}_{2} \mathrm{O}\right)$ value.

When the IP is understood as the preparation time for surface nucleation, its elementary physico-chemical steps can be deduced from the classical nucleation theory. ${ }^{1-3,69-72}$ Three elementary steps, which occur successively, 
can be formulated on the basis of the classical nucleation theory, i.e., (1) desorption of water molecules from the surface, (2) creation of water vacancy, and (3) precipitation of the product phase through the combination of $\mathrm{Li}^{+}$, $\mathrm{SO}_{4}{ }^{2-}$, and water vacancy. The hypothetical process of surface nucleation, which is assumed to be a chemical event occurring during the IP, is schematically illustrated in Figure S10, and listed in Table 1 using Kröger's notation. ${ }^{73}$ When one of these elementary steps is identified as the rate-limiting step and the other steps are assumed to be at an equilibrium condition, three different kinetic equations can be derived, as listed in Table 1. The kinetic equations for processes (1) and (2) can be reduced to the following equation in cases where $1 \gg K_{3}{ }^{1 / n} K_{2}$ or $1<<K_{3}{ }^{1 / n} K_{2}$ for process (1) and $K_{1} \ll p\left(\mathrm{H}_{2} \mathrm{O}\right) / \mathrm{P}^{\circ}$ for process (2):

$$
v=k^{\prime}\left(1-\frac{p\left(\mathrm{H}_{2} \mathrm{O}\right)}{P_{\mathrm{eq}}(T)}\right)
$$

where $k^{\prime}, p\left(\mathrm{H}_{2} \mathrm{O}\right)$, and $P_{\mathrm{eq}}(T)$ are the apparent rate constant, water vapor pressure, and equilibrium pressure for the thermal dehydration of LSM, respectively. For process (3), the kinetic equation is simplified to:

$$
v=k^{\prime \prime}\left(\frac{P^{\circ}}{p\left(\mathrm{H}_{2} \mathrm{O}\right)}\right)^{n}\left[1-\left(\frac{p\left(\mathrm{H}_{2} \mathrm{O}\right)}{P_{\mathrm{eq}}(T)}\right)^{n}\right]
$$

where $k^{\prime \prime}$ is the rate constant and $P^{\circ}$ is the standard pressure introduced to normalize the unit of the pressure terms. Both Eqs. (4) and (5) comprise $p\left(\mathrm{H}_{2} \mathrm{O}\right)$ and $P_{\mathrm{eq}}(T)$ in the kinetic expression, but these are not involved in Eq. (3). Thus, an accommodation function (AF) of $a\left(p\left(\mathrm{H}_{2} \mathrm{O}\right), P_{\mathrm{eq}}(T)\right)$ should be introduced into the kinetic equation to universally describe the kinetic behavior at various $p\left(\mathrm{H}_{2} \mathrm{O}\right)$ values. ${ }^{58-59}$

$$
\frac{1}{t_{\mathrm{IP}}}=A_{\mathrm{IP}} \exp \left(-\frac{E_{\mathrm{a}, \mathrm{IP}}}{R T}\right) f\left(\alpha_{\mathrm{IP}}\right) a\left(p\left(\mathrm{H}_{2} \mathrm{O}\right), P_{\mathrm{eq}}(T)\right)
$$

The following AF is formulated as an analytical form based on Eqs. (4) and (5): $58-59$

$$
a\left(p\left(\mathrm{H}_{2} \mathrm{O}\right), P_{\mathrm{eq}}(T)\right)=\left(\frac{P^{\circ}}{p\left(\mathrm{H}_{2} \mathrm{O}\right)}\right)^{a}\left[1-\left(\frac{p\left(\mathrm{H}_{2} \mathrm{O}\right)}{P_{\mathrm{eq}}(T)}\right)^{b}\right]
$$

where exponents $(a, b)$ are constants. The analytical form of the AF of Eq. (7) corresponds to the kinetic equations in Eqs. (4) and (5) when $(a, b)=(0,1)$ and $a=b$, respectively, although the ideal situations are only expected based on the simple rate-limiting step and steady-state approximations. By extending the interpretation of the AF, the case of $a \neq b$ can be obtained, indicating more complex interactions between the component elementary steps with respect to the $p\left(\mathrm{H}_{2} \mathrm{O}\right)$ value. 
Table 1. Elementary steps assumed for the surface nucleation of the thermal dehydration of LSM and the kinetic equations derived based on the simple rate-limiting step and steady-state approximations

\begin{tabular}{|c|c|c|c|c|}
\hline & Elementary step & Reaction & Equilibrium constant, $K_{i}$ & $\begin{array}{c}\text { Overall rate } v \text { for the process controlled by } \\
\text { the elementary step } i\end{array}$ \\
\hline (1) & $\begin{array}{l}\text { Desorption step of water } \\
\text { molecules from the surface }\end{array}$ & $\mathrm{H}_{2} \mathrm{O}-(\mathrm{s}) \rightleftarrows \mathrm{H}_{2} \mathrm{O}(\mathrm{g})+(\mathrm{s})$ & $K_{1}=\frac{\frac{[(\mathrm{s})] p_{\mathrm{H}_{2} \mathrm{O}}}{P^{\circ}}}{\left[\mathrm{H}_{2} \mathrm{O}-(\mathrm{s})\right]}$ & $v_{1}=k_{1} \frac{K_{3}^{1 / n} K_{2}}{1+K_{3}^{1 / n} K_{2}}\left(1-\frac{p\left(\mathrm{H}_{2} \mathrm{O}\right)}{P_{\mathrm{eq}}(T)}\right)$ \\
\hline (2) & Water vacancy creation & $\mathrm{H}_{2} \mathrm{O}_{\mathrm{H}_{2} \mathrm{O}}+(\mathrm{s}) \rightleftarrows \mathrm{H}_{2} \mathrm{O}-(\mathrm{s})+\mathrm{V}_{\mathrm{H}_{2} \mathrm{O}}$ & $K_{2}=\frac{\left[\mathrm{H}_{2} \mathrm{O}-(\mathrm{s})\right]\left[\mathrm{V}_{\mathrm{H}_{2} \mathrm{O}}\right]}{[(\mathrm{s})]}$ & $v_{2}=k_{2} \frac{K_{1}}{K_{1}+\frac{p\left(\mathrm{H}_{2} \mathrm{O}\right)}{\mathrm{P}^{\circ}}}\left(1-\frac{p\left(\mathrm{H}_{2} \mathrm{O}\right)}{P_{\mathrm{eq}}(T)}\right)$ \\
\hline (3) & $\begin{array}{l}\text { "Precipitation" of the product } \\
\text { phase }\end{array}$ & $n\left[2 \mathrm{Li}_{\mathrm{Li}}+\mathrm{SO}_{4, \mathrm{SO}_{4}}+\mathrm{V}_{\mathrm{H}_{2} \mathrm{O}}\right]_{h} \rightleftarrows n\left[2 \mathrm{Li} \mathrm{Li}+\mathrm{SO}_{4, \mathrm{SO}_{4}}\right]_{a}$ & $K_{3}=\frac{1}{\left[\mathrm{~V}_{\mathrm{H}_{2} \mathrm{O}}\right]^{n}}$ & $v_{3}=k_{3}\left(\frac{K_{1} K_{2}}{\frac{p\left(\mathrm{H}_{2} \mathrm{O}\right)}{\mathrm{P}^{\circ}}}\right)$ \\
\hline
\end{tabular}


The analytical form of AF in Eq. (7) with $(a, b)=(0,1)$ is equivalent to one of those conventionally used as the $\mathrm{AF}$ for describing the influence of the partial pressure of the product gas on the overall kinetics of the thermal decomposition of solids. ${ }^{50,74-82}$ The Arrhenius plot for the IP, modified by introducing the AF, is generally expressed by Eq. (8).

$$
\ln \left[\frac{1}{t_{\mathrm{IP}} \cdot a\left(p\left(\mathrm{H}_{2} \mathrm{O}\right), P_{\mathrm{eq}}(T)\right)}\right]=\ln \left[A_{\mathrm{IP}} f\left(\alpha_{\mathrm{IP}}\right)\right]-\frac{E_{\mathrm{a}, \mathrm{IP}}}{R T}
$$

The Arrhenius plots modified by introducing the AF with $(a, b)=(0,1)$ are shown in Figure S11. The modified Arrhenius plot exhibits different linear correlations for the IP at different $p\left(\mathrm{H}_{2} \mathrm{O}\right)$ values, as is the case for the conventional Arrhenius plot (Figure S9). Table S3 lists the apparent Arrhenius parameters determined by the modified Arrhenius plot. The apparent Arrhenius parameters are also comparable with those determined by the conventional Arrhenius plot (Table S2). Therefore, the Arrhenius plot modified by introducing the conventional AF, i.e., Eq. (7) with $(a, b)=(0,1)$, does not achieve the universal kinetic description of the IP over different $p\left(\mathrm{H}_{2} \mathrm{O}\right)$ values. A simple consideration of the successive elementary steps based on the rate-limiting step and steady-state approximations also provides the possible form of AF in Eq. (7) with $a=b$, where the precipitation of the product phase is assumed as the rate-limiting step. Figure S12 shows the modified Arrhenius plot with the AF in Eq. (7) under the restricted conditions of $a=b$. By optimizing $a$ and $b$ values $(a=b)$, all data points obtained under different temperatures and $p\left(\mathrm{H}_{2} \mathrm{O}\right)$ values can be correlated on the Arrhenius coordinate to the left-hand side of Eq. (8) versus the reciprocal temperature (Figure S12(a)); however, an apparent break of the Arrhenius plot is observed at approximately $371 \mathrm{~K}$. Therefore, the modified Arrhenius plots are reexamined in two temperature regions, i.e., above and below $371 \mathrm{~K}$ (Figure S12(b)). The modified Arrhenius plots in the two different temperature regions indicate statistically significant linear correlations of better than -0.99 . The optimized exponents $(a=b)$ and the resulting Arrhenius parameters are listed in Table S4. Larger exponents $(a, b)$ are observed for the IP in the lower temperature region. The opposite is observed for the Arrhenius parameters $\left(E_{\mathrm{a}, \mathrm{IP}}, \ln \left[A_{\mathrm{IP}} f\left(\alpha_{\mathrm{IP}}\right)\right]\right)$, i.e., smaller Arrhenius parameter values are observed in the lower temperature region.

Figure 7 shows the modified Arrhenius plots for the IP with the AF without any restriction on the exponents $(a, b)$, i.e., $a \neq b$. The modified Arrhenius plot again exhibits a break at approximately $371 \mathrm{~K}$ (Figure 7(a)). The modified Arrhenius plots in the two temperature regions of above and below $371 \mathrm{~K}$ exhibit statistically significant linear correlations, including all data points for the different temperatures and $p\left(\mathrm{H}_{2} \mathrm{O}\right)$ values (Figure 7(b)). Table 2 lists the exponents $(a, b)$ and Arrhenius parameters $\left(E_{\mathrm{a}, \mathrm{IP}}, \ln \left[A_{\mathrm{IP}} f\left(\alpha_{\mathrm{IP}}\right)\right]\right)$ determined through the modified Arrhenius plots shown in Figure 7(b). The optimized exponent $a$ for the IP in each temperature region is nearly identical to that calculated under the restriction of $a=b$. However, the exponent $b$ is determined to be approximately unity in both temperature regions, which is a much smaller value than that determined under the restriction of $a=b$. Because the statistical significances of the Arrhenius plots drawn assuming $a=b$ and $a \neq b$ are comparable, a universal description of the kinetic behavior by the modified Arrhenius plot is enabled by the contribution of the first part of the AF in Eq. (7) with exponent $a$. The dispensable role of the second part of the AF with exponent $b$ is explained by the relation of $P_{\text {eq }}(T)$ and the experimentally controlled $p\left(\mathrm{H}_{2} \mathrm{O}\right)$ value applied in this study. Figure $\mathrm{S} 13$ shows the $P_{\text {eq }}$ values at different temperatures, together with the experimentally applied $p\left(\mathrm{H}_{2} \mathrm{O}\right)$ values. Because the $p\left(\mathrm{H}_{2} \mathrm{O}\right)$ values are much smaller than the $P_{\text {eq }}$ values over the temperature range of the measurements, the value of $p\left(\mathrm{H}_{2} \mathrm{O}\right) / P_{\text {eq }}(T)$ is negligible. Therefore, the second part of the AF in Eq. (7) is necessarily unity. A smaller set of 
values of Arrhenius parameters $\left(E_{\mathrm{a}, \mathrm{IP}}, \ln \left[A_{\mathrm{IP}} f\left(\alpha_{\mathrm{IP}}\right)\right]\right)$ were obtained for the IP at temperatures lower than $371 \mathrm{~K}$. The boundary temperature of $371 \mathrm{~K}$ is close to the boiling point of $\mathrm{H}_{2} \mathrm{O}$ at the standard pressure. Therefore, the absorption/condensation of $\mathrm{H}_{2} \mathrm{O}$ in some elementary steps of the IP (as listed in Table 1 and illustrated in Figure $\mathrm{S} 10$ ) is a possible cause of the different kinetic behaviors in the temperature regions above and below $371 \mathrm{~K}$. In the temperature region lower than $373 \mathrm{~K}$ and at $p\left(\mathrm{H}_{2} \mathrm{O}\right)$ values lower than $1 \mathrm{kPa}$, Seto et al. ${ }^{49}$ observed Smith-Topleylike behavior characterized by an initial decrease and subsequent increase in the reaction rate of the mass-loss process with increasing $p\left(\mathrm{H}_{2} \mathrm{O}\right)$ value. The formation of an amorphous product under the aforementioned temperature and $p\left(\mathrm{H}_{2} \mathrm{O}\right)$ conditions and the absorption of the dissociated $\mathrm{H}_{2} \mathrm{O}$ were discussed as the possible causes of this unusual phenomenon. Because the reaction conditions are practically comparable, some consistency between the phenomenon observed for the IP in this study and that observed by Seto et al. ${ }^{49}$ for the mass-loss process can be expected.
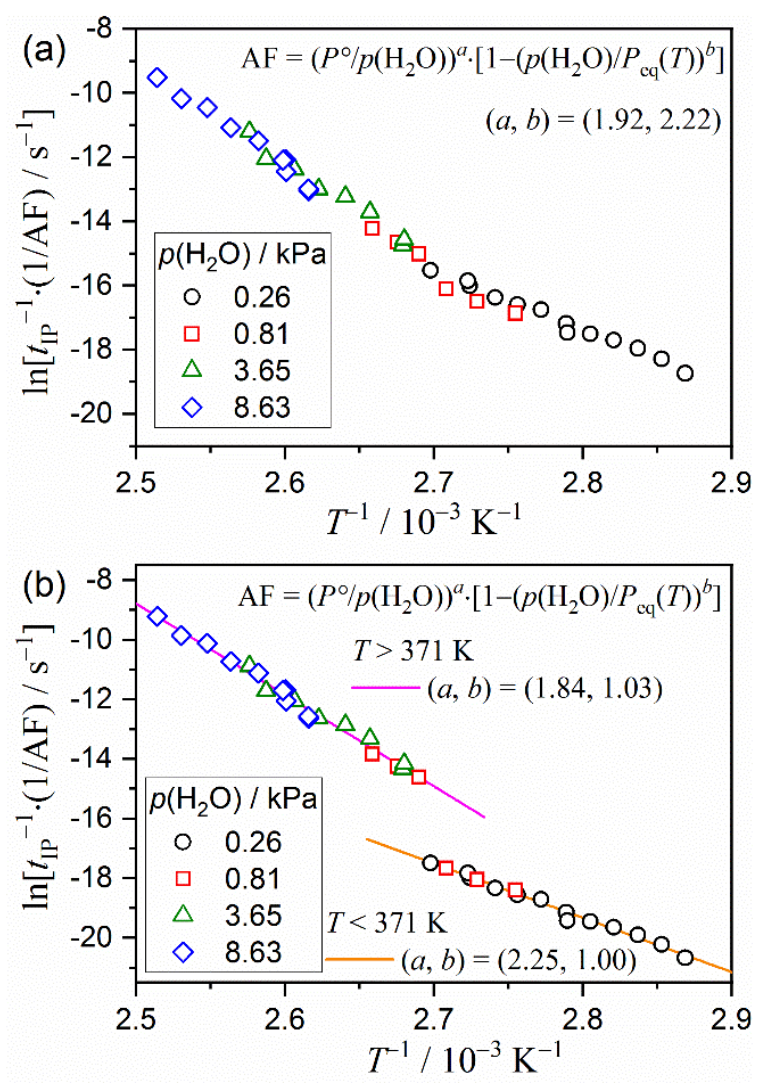

Figure 7. Arrhenius plot modified by the AF in Eq. (7) without any restriction on the exponents $(a, b)$, applied to the IP of the thermal dehydration of LSM in (a) the entire temperature region and (b) two separated temperature regions of above and below $371 \mathrm{~K}$.

Table 2. Kinetic parameters for the IP of the thermal dehydration of LSM, determined through the Arrhenius plots modified by introducing the AF in Eq. (7) without any restriction on the exponents $(a, b)$

\begin{tabular}{cccccc}
\hline Temperature region & $a$ & $b$ & $E_{\mathrm{a}, \mathrm{IP}} / \mathrm{kJ} \mathrm{mol}^{-1}$ & $\ln \left[A_{\mathrm{IP}} f\left(\alpha_{\mathrm{IP}}\right) / \mathrm{s}^{-1}\right]$ & $-\gamma^{\mathrm{a}}$ \\
\hline$T<371 \mathrm{~K}$ & 2.25 & 1.00 & $151.4 \pm 4.3$ & $31.6 \pm 1.5$ & 0.9946 \\
$T>371 \mathrm{~K}$ & 1.84 & 1.03 & $254.8 \pm 6.7$ & $67.8 \pm 2.1$ & 0.9935 \\
\hline
\end{tabular}


${ }^{\mathrm{a}}$ Correlation coefficient of the linear regression analysis.

\subsection{Formal kinetic description for the thermal dehydration process}

The mass-loss processes of the thermal dehydration of LSM under different $p\left(\mathrm{H}_{2} \mathrm{O}\right)$ values are subjected to formal kinetic analysis using the mass-loss curves recorded under isothermal and linear nonisothermal conditions at four selected $p\left(\mathrm{H}_{2} \mathrm{O}\right)$ values, i.e., $0.26,0.81,3.65$, and $8.71 \mathrm{kPa}$, as average values. The isothermal mass-loss curves are shown in Figure 5. Figure 8 shows the mass-loss curves recorded at different $\beta$ values for the reactions under different $p\left(\mathrm{H}_{2} \mathrm{O}\right)$ values. Irrespective of the $p\left(\mathrm{H}_{2} \mathrm{O}\right)$ value, the mass-loss curves systematically shift to higher temperatures with increasing $\beta$ value, indicating the general behavior of the kinetic process. Besides the mass-loss curves recorded under isothermal and linear nonisothermal conditions, those recorded under CRTA conditions applied to the reactions at $p\left(\mathrm{H}_{2} \mathrm{O}\right)=0.26 \mathrm{kPa}$ (shown in Figure S14) are also used for the kinetic calculations. A constant mass-loss rate is realized during the mass-loss process by controlling the sample temperature using the feedback signal of the mass-loss rate (Figure S14(a)). With increasing $C$ value, the reaction temperature shifts systematically to higher values (Figure S14(b)), maintaining the kinetic relation between the reaction rate and temperature observed for the mass-loss curves recorded under isothermal and linear nonisothermal conditions. The sigmoidal feature of the mass-loss curve observed under isothermal conditions inversely appears as the temperature drop in the initial part and temperature rise in the final part of the reaction when the mass-loss rate is regulated to be constant in the CRTA.
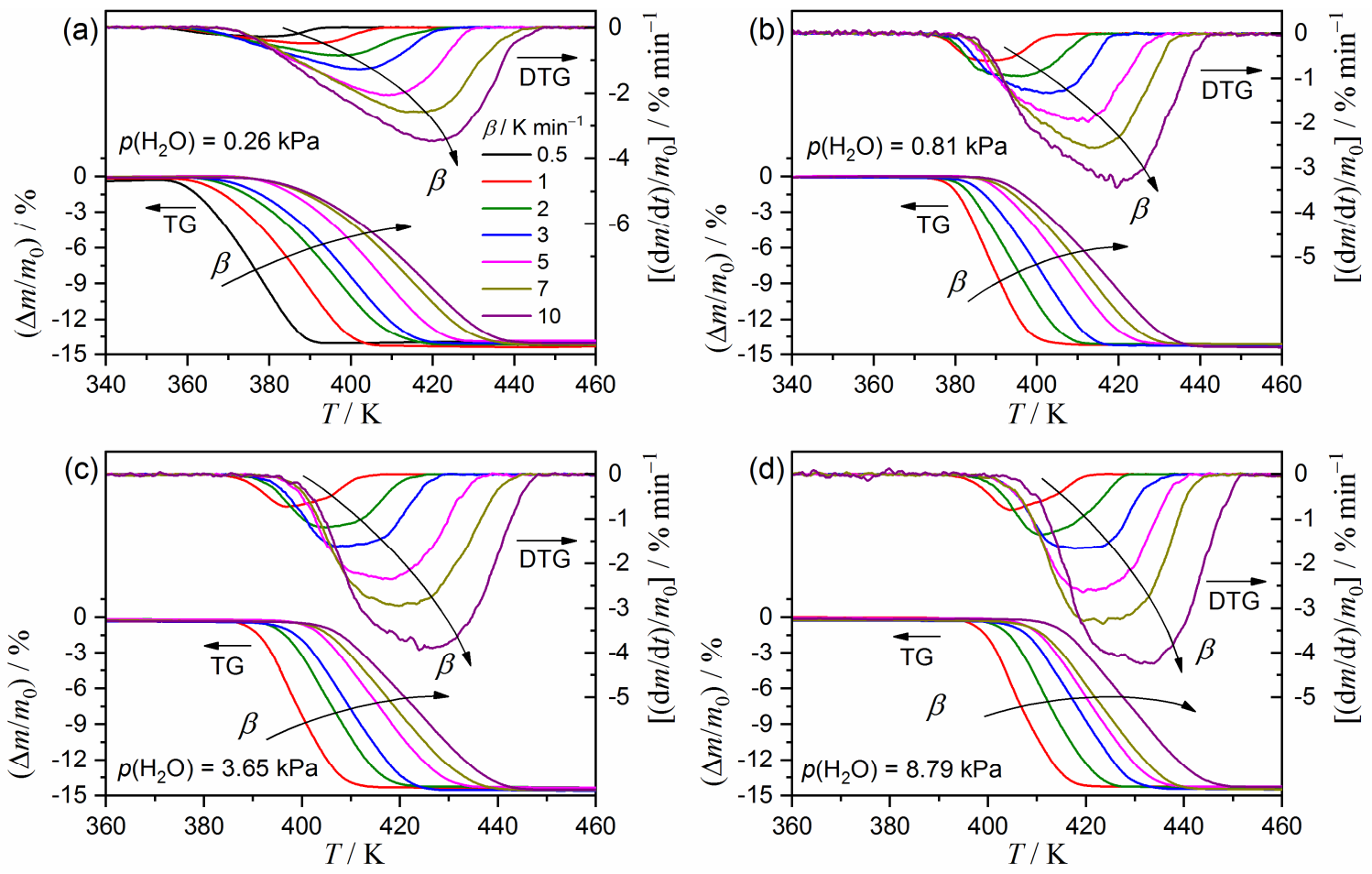

Figure 8. Mass-loss curves for the thermal dehydration of LSM recorded at different $\beta$ values in flowing wet $\mathrm{N}_{2}$ gas with different controlled $p\left(\mathrm{H}_{2} \mathrm{O}\right)$ values: (a) $0.26 \mathrm{kPa}\left(m_{0}=5.175 \pm 0.136 \mathrm{mg}\right)$, (b) $0.81 \mathrm{kPa}\left(m_{0}=5.115 \pm 0.112\right.$ $\mathrm{mg})$, (c) $3.65 \mathrm{kPa}\left(m_{0}=5.456 \pm 0.490 \mathrm{mg}\right)$, and (d) $8.79 \mathrm{kPa}\left(m_{0}=5.147 \pm 0.453 \mathrm{mg}\right)$. 
Conventionally, the kinetic behavior of thermal dehydration is described by the fundamental kinetic equation presented as Eq. (1), with the assumption of a single-step process and without considering the influence of atmospheric $p\left(\mathrm{H}_{2} \mathrm{O}\right)$. Taking logarithms of Eq. (1), one can obtain:

$$
\ln \left(\frac{\mathrm{d} \alpha}{\mathrm{d} t}\right)=\ln [A f(\alpha)]-\frac{E_{\mathrm{a}}}{R T}
$$

Ideally, the plot of $\ln (\mathrm{d} \alpha / \mathrm{d} t)$ versus $T^{-1}$ applied to the data points at a selected $\alpha$ value, as read from the kinetic data converted from the mass-loss curves recorded under different heating conditions, is a straight line because the logarithmic term on the right-hand side of Eq. (9), i.e., $\ln [A f(\alpha)]$, is constant. Based on the isoconversional plot applied to the derivative kinetic data based on Eq. (9), known as the Friedman plot, ${ }^{83}$ the $E_{\mathrm{a}}$ value at the selected $\alpha$ is calculated from the slope, i.e., $-E_{\mathrm{a}} / R$. Figure 9 shows the results of kinetic calculation based on the conventional Friedman plot. Different Friedman plots are obtained for the kinetic data recorded at different $p\left(\mathrm{H}_{2} \mathrm{O}\right)$ values, although each Friedman plot at a selected $p\left(\mathrm{H}_{2} \mathrm{O}\right)$ value exhibits statistically significant linear correlations, including the data points recorded under different heating conditions, i.e., isothermal, linear nonisothermal, and CRTA conditions (Figure 9(a)). The slope of the conventional Friedman plot increases systematically with increasing $p\left(\mathrm{H}_{2} \mathrm{O}\right)$ value. This behavior is observed irrespective of the selected $\alpha$ value, as shown in Figure $\mathrm{S} 15$ for $\alpha$ values ranging from 0.1 to 0.9 in steps of 0.1 . Thus, larger apparent $E_{\mathrm{a}}$ values are obtained for the reactions at greater $p\left(\mathrm{H}_{2} \mathrm{O}\right)$ values. The variation trends in the slope of the conventional Friedman plots, and thus, the apparent $E_{\mathrm{a}}$ value, as the reaction advances also change depending on the $p\left(\mathrm{H}_{2} \mathrm{O}\right)$ value. Generally, irrespective of the applied $p\left(\mathrm{H}_{2} \mathrm{O}\right)$ values, a decrease in the apparent $E_{\mathrm{a}}$ value is observed in the initial part of the mass-loss process (Figure 9(b)). However, the range of the initial $E_{\mathrm{a}}$ decrease increases with the $p\left(\mathrm{H}_{2} \mathrm{O}\right)$ value. After the initial decrease, the $E_{\mathrm{a}}$ values for the reactions at each $p\left(\mathrm{H}_{2} \mathrm{O}\right)$ value are maintained at approximately constant values. Table S5 list the average $E_{\mathrm{a}}$ value in the $\alpha$ range of the constant $E_{\mathrm{a}}$ value. The average $E_{\mathrm{a}}$ value also increases with the $p\left(\mathrm{H}_{2} \mathrm{O}\right)$ value.

For the mass-loss process at the lowest $p\left(\mathrm{H}_{2} \mathrm{O}\right)$ value, i.e., $0.26 \mathrm{kPa}$, the apparent $E_{\text {a }}$ value is approximately constant across a wide $\alpha$ range of $0.1 \leq \alpha \leq 0.9$, with an average value of $86.4 \pm 2.0 \mathrm{~kJ} \mathrm{~mol}^{-1}$. Thus, the mass-loss process at $p\left(\mathrm{H}_{2} \mathrm{O}\right)=0.26 \mathrm{kPa}$ can be approximated as a single-step reaction, whereas the processes at higher $p\left(\mathrm{H}_{2} \mathrm{O}\right)$ values are interpreted as a multistep process because of the larger contribution of the initial decreasing $E_{\mathrm{a}}$ part. For the single-step reaction characterized by a constant $E_{\mathrm{a}}$ during the overall reaction, the experimental master plot can be drawn by calculating the hypothetical reaction rate at infinite temperature at various $\alpha$ values, according to Eq. (10). ${ }^{84-89}$

$$
\begin{aligned}
& \left(\frac{\mathrm{d} \alpha}{\mathrm{d} \theta}\right)=\left(\frac{\mathrm{d} \alpha}{\mathrm{d} t}\right) \exp \left(\frac{E_{\mathrm{a}}}{R T}\right)=A f(\alpha) \\
& \text { with } \quad \theta=\int_{0}^{t} \exp \left(-\frac{E_{\mathrm{a}}}{R T}\right) \mathrm{d} t
\end{aligned}
$$

where $\theta$ is Ozawa's generalized time. ${ }^{90-91}$ Figure $\mathrm{S} 16$ shows the experimental master plot of $(\mathrm{d} \alpha / \mathrm{d} \theta)$ versus $\alpha$ for the mass-loss process at $p\left(\mathrm{H}_{2} \mathrm{O}\right)=0.26 \mathrm{kPa}$. The experimental master plot exhibits a deceleration process that is convex in shape. The experimental master plot can be correlated with $A f(\alpha)$ according to Eq. (10). From the shape of the experimental master plot, a PBR model, $R(n)$, can be selected as the appropriate kinetic model function.

$$
R(n): f(\alpha)=n(1-\alpha)^{1-1 / n}
$$

where $n$ is the shrinkage dimension of the reaction interface. The empirical optimization of the $n$ value through nonlinear least squares analysis to fit the experimental master plot yield $n=4.14 \pm 0.06$, which is larger than the 
theoretically acceptable value, i.e., $1 \leq n \leq 3$. The possible contribution of the surface reaction process during the initial part of the overall mass-loss process, which is inevitable even at the lowest $p\left(\mathrm{H}_{2} \mathrm{O}\right)$ value examined, is considered one of the reasons for the discrepancy of the actual rate behavior and the theoretical reaction model.
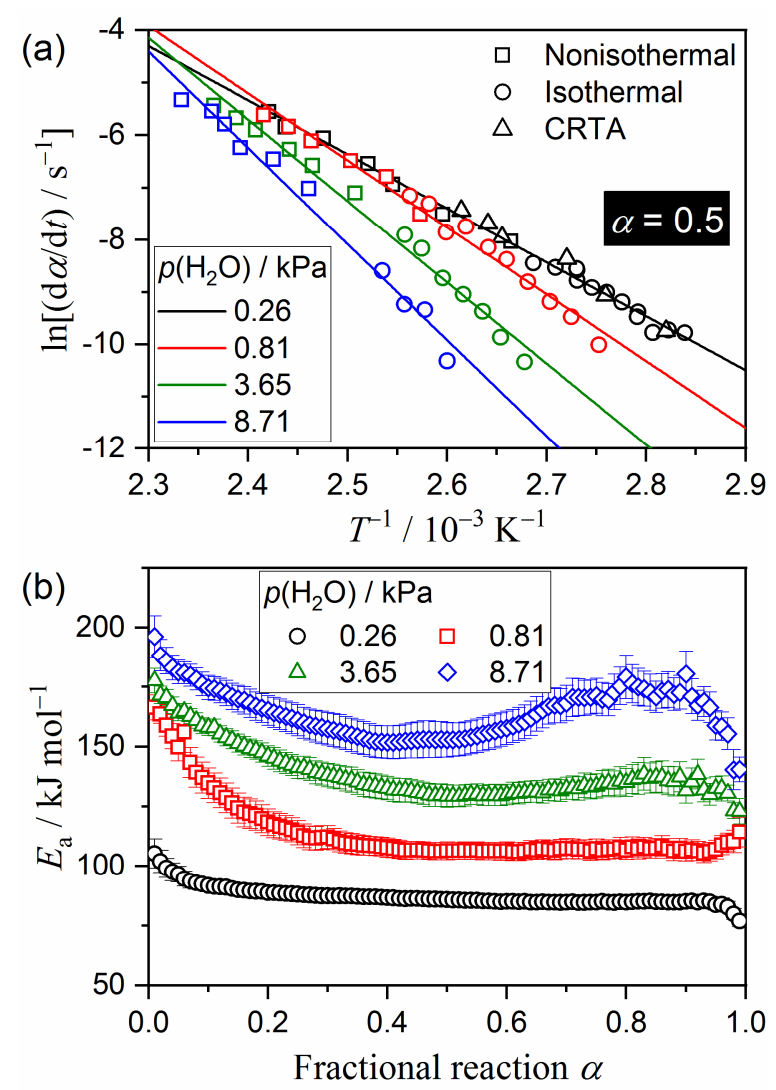

Figure 9. Results of the kinetic calculation based on the conventional Friedman plot: (a) Friedman plots at $\alpha=0.5$

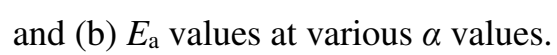

From the results of the conventional isoconversional analysis, it is evident that the kinetics of the mass-loss process of the thermal dehydration of LSM are significantly influenced by the atmospheric $p\left(\mathrm{H}_{2} \mathrm{O}\right)$ value; as such, the conventional isoconversional analysis cannot universally describe the kinetic behaviors over different temperature and $p\left(\mathrm{H}_{2} \mathrm{O}\right)$ conditions. As in the case of the kinetic analysis for the IP, the introduction of an appropriate $\mathrm{AF}$ in the kinetic equation for the mass-loss process is one potential way to express the kinetic behavior over different temperature and $p\left(\mathrm{H}_{2} \mathrm{O}\right)$ conditions: ${ }^{58-59}$

$$
\frac{\mathrm{d} \alpha}{\mathrm{d} t}=A \exp \left(-\frac{E_{\mathrm{a}}}{R T}\right) f(\alpha) a\left(p\left(\mathrm{H}_{2} \mathrm{O}\right), P_{\mathrm{eq}}(T)\right)
$$

The overall mass-loss process proceeds via advancement of the reaction interface, subsequent to the surface reaction process described in Table 1. Therefore, the influence of $p\left(\mathrm{H}_{2} \mathrm{O}\right)$ on the interface reaction process is considered based on the classical interface reaction theory ${ }^{1-3,} 69-72$ as the successive process of five elementary steps, as schematically shown in Figure S17. Table 3 lists the equilibrium constant of each component elementary step and the kinetic equations derived by selecting one rate-limiting step while assuming that the other elementary steps are 
at equilibrium. These five kinetic equations are simplified into two kinetic equations, which are equivalent to those derived for the IP, i.e., Eqs. (4) and (5). Thus, Eq. (7) is also used as the analytical form of the AF for the interface reaction. By introducing the $\mathrm{AF}$, the Friedman plot is modified as:

$$
\ln \left[\left(\frac{\mathrm{d} \alpha}{\mathrm{d} t}\right) \cdot \frac{1}{a\left(p\left(\mathrm{H}_{2} \mathrm{O}\right), P_{\mathrm{eq}}(T)\right)}\right]=\ln [A f(\alpha)]-\frac{E_{\mathrm{a}}}{R T}
$$

By combining Eq. (13) with the AF in Eq. (7), all the mass-loss curves recorded under different heating and $p\left(\mathrm{H}_{2} \mathrm{O}\right)$ conditions are simultaneously examined by the modified Friedman plot at each $\alpha$ value, through which the exponents $(a, b)$ in the $\mathrm{AF}$ in Eq. (7) are optimized to provide the best linearity of the plot. 
Table 3. Elementary steps assumed for the interface reaction of the thermal dehydration of LSM and the kinetic equations derived based on the simple rate-limiting step and steady-state approximations

\begin{tabular}{|c|c|c|c|c|}
\hline & Elementary step & Reaction & Equilibrium constant, $K_{i}$ & $\begin{array}{c}\text { Overall rate } v \text { for the process controlled by } \\
\text { the elementary step } i\end{array}$ \\
\hline (1) & $\begin{array}{l}\text { Desorption step of water } \\
\text { molecules from the surface }\end{array}$ & $\mathrm{H}_{2} \mathrm{O}-(\mathrm{s}) \rightleftarrows \mathrm{H}_{2} \mathrm{O}(\mathrm{g})+(\mathrm{s})$ & $K_{1}=\frac{[(\mathrm{s})] p_{\mathrm{H}_{2} \mathrm{O}} / P^{\circ}}{\left[\mathrm{H}_{2} \mathrm{O}-(\mathrm{s})\right]}$ & $v_{1}=k_{1} \frac{K_{2} K_{4} K_{5}}{1+K_{2} K_{4} K_{5}}\left(1-\frac{p_{\mathrm{H}_{2} \mathrm{O}}}{P_{\mathrm{eq}}}\right)$ \\
\hline (2) & External interface & $\mathrm{H}_{2} \mathrm{O}_{i, e x t}+(\mathrm{s}) \rightleftarrows \mathrm{H}_{2} \mathrm{O}-(\mathrm{s})$ & $K_{2}=\frac{\left[\mathrm{H}_{2} \mathrm{O}-(\mathrm{s})\right]}{\left[\mathrm{H}_{2} \mathrm{O}_{i, \text { ext }}\right][(\mathrm{s})]}$ & $v_{2}=k_{2} K_{4} K_{5}\left(1-\frac{p_{\mathrm{H}_{2} \mathrm{O}}}{P_{\mathrm{eq}}}\right)$ \\
\hline (3) & Diffusion of interstitials & $\mathrm{H}_{2} \mathrm{O}_{i, i n t} \rightleftarrows \mathrm{H}_{2} \mathrm{O}_{i, \text { ext }}$ & {$\left[\mathrm{H}_{2} \mathrm{O}_{i, e x t}\right]=\left[\mathrm{H}_{2} \mathrm{O}_{i, i n t}\right]$} & $v_{3}=\frac{D_{\mathrm{H}_{2} \mathrm{O}_{i}}}{l_{0}} K_{4} K_{5}\left(1-\frac{p_{\mathrm{H}_{2} \mathrm{O}}}{P_{\mathrm{eq}}}\right)$ \\
\hline (4) & $\begin{array}{l}\text { Creation of interstitial at the } \\
\text { internal interface }\end{array}$ & $\mathrm{H}_{2} \mathrm{O}_{\mathrm{H}_{2} \mathrm{O}} \rightleftarrows \mathrm{H}_{2} \mathrm{O}_{i, \text { int }}+\mathrm{V}_{\mathrm{H}_{2} \mathrm{O}}$ & $K_{4}=\left[\mathrm{H}_{2} \mathrm{O}_{i, i n t}\right]\left[\mathrm{V}_{\mathrm{H}_{2} \mathrm{O}}\right]$ & $v_{4}=k_{4}\left(1-\frac{p_{\mathrm{H}_{2} \mathrm{O}}}{P_{\mathrm{eq}}}\right)$ \\
\hline (5) & $\begin{array}{l}\text { Creation of a building unit of } \\
\mathrm{Li}_{2} \mathrm{SO}_{4} \text { at internal interface }\end{array}$ & $n\left[2 \mathrm{Li}_{\mathrm{Li}}+\mathrm{SO}_{4, \mathrm{SO}_{4}}+\mathrm{V}_{\mathrm{H}_{2} \mathrm{O}}\right]_{h} \rightleftarrows n\left[2 \mathrm{Li}_{\mathrm{Li}}+\mathrm{SO}_{4, \mathrm{SO}_{4}}\right]_{a}$ & $K_{5}=\frac{1}{\left[\mathrm{~V}_{\mathrm{H}_{2} \mathrm{O}}\right]^{n}}$ & $v_{5}=k_{5}\left(\frac{K_{1} K_{2} K_{4}}{p_{\mathrm{H}_{2} \mathrm{O}} / P^{\circ}}\right)^{n}\left(1-\frac{p_{\mathrm{H}_{2} \mathrm{O}}^{n}}{P_{\mathrm{eq}}^{n}}\right)$ \\
\hline
\end{tabular}


As in the case of the IP, introduction of the conventional AF with $(a, b)=(0,1)$ in Eq. (7) does not improve the conventional Friedman plot (Figure 9). Thus, the $(a, b)$ values are optimized through the modified Friedman plot with and without the restriction of $a=b$. Figure S18 shows typical results of the Friedman plots modified using the AF in Eq. (7) without the restriction of $a=b$ at different $\alpha$ values ranging from 0.1 to 0.9 in steps of 0.1 . In the plots for $\alpha \geq 0.5$, all data points recorded under different temperature and $p\left(\mathrm{H}_{2} \mathrm{O}\right)$ conditions are described by a single Friedman plot with a statistically significant linear correlation. A bending of the plot at approximately $371 \mathrm{~K}$ is observed during the initial stage of the reaction, i.e., $\alpha<0.4$, similar to the modified Arrhenius plot for the IP (Figure 7(a)). Figure S19 shows the optimized $(a, b)$ values and the apparent $E_{\mathrm{a}}$ values at various $\alpha$ values obtained by the modified Friedman plots applied to all data points, by neglecting the possible bending of the plots during the initial stage of the reaction. Both $(a, b)$ values decrease during the initial stage of the reaction (Figure S19(a)). Subsequently, the $a$ value increases slightly toward the end of the reaction, i.e., from approximately 0.5 to 0.75 during the second half of the reaction. However, $b$ maintains a constant value of approximately 0.5 across a wide $\alpha$ range of $0.2-0.95$. The apparent $E_{\mathrm{a}}$ value also decreases from approximately 160 to $105 \mathrm{~kJ} \mathrm{~mol}^{-1}$ during the first half of the reaction, and subsequently, increases slightly from 105 to $110 \mathrm{~kJ} \mathrm{~mol}^{-1}$ (Figure S19(b)). The variation in $E_{\mathrm{a}}$ values is apparently synchronized with that of $a$ values in the AF. The results of the modified Friedman plots with the restriction of $a=b$ in the AF of Eq. (7) are practically identical to the results obtained without the restriction, as shown in Figures S20 and S21. In contrast, a notable difference in the $b$ values is observed between the results obtained with and without the restriction of $a=b$. When the restriction of $a=b$ was applied, the $b$ value is influenced by the $a$ value, indicating the major contribution of the $a$ value, thus the first part of the AF, to realize the universal kinetic description of the reactions at different temperatures and $p\left(\mathrm{H}_{2} \mathrm{O}\right)$ values.

For further sophisticated application of the modified Friedman plot with the AF in Eq. (7), the plots are examined in the separated temperature regions, i.e., above and below $371 \mathrm{~K}$. Typical results of the modified Friedman plots applied without the restriction of $a=b$ are shown in Figure 10 by selecting those at $\alpha=0.1$ and 0.5 . At $\alpha=0.1$, the two Friedman plots applied to the data points in the different temperature regions exhibit apparently different slopes, where the slope for the higher temperatures is larger than that for the lower temperature region. Note also that the statistically significant linear correlations of the data points in each temperature region are enabled by the different sets of $(a, b)$ values. At $\alpha=0.5$, the modified Friedman plots in the different temperature regions are characterized by parallel straight lines. However, the set of $(a, b)$ values that realize the linear correlation in each temperature region differ between the two plots. Figure S22 shows the modified Friedman plots $(a \neq b)$ for the data points in the different temperature regions at various $\alpha$ values from 0.1 to 0.9 in steps of 0.1 . Slopes of the plots in the different temperature regions gradually become parallel as the reaction advances and coincide at $\alpha>0.4$. Thus, the specific kinetic behavior in the temperature region below $371 \mathrm{~K}$ and $p\left(\mathrm{H}_{2} \mathrm{O}\right)$ region below $1 \mathrm{kPa}$ revealed for the IP process is continuously observed in the initial stage of the mass-loss process $(\alpha<0.4)$ under the same temperature and $p\left(\mathrm{H}_{2} \mathrm{O}\right)$ conditions. From the physico-geometrical consideration of the thermal dehydration, the IP and subsequent initial part of the mass-loss process characterize the kinetic feature of the SR process. If the specific kinetic behavior is relevant to the Smith-Topley-like behavior observed under the same reaction conditions as those described by Seto et al., ${ }^{49}$ the impact of $p\left(\mathrm{H}_{2} \mathrm{O}\right)$ on surface nucleation and the subsequent growth of the nuclei on the reactant surfaces can be considered as a possible cause of the exotic rate behavior dependence of atmospheric $p\left(\mathrm{H}_{2} \mathrm{O}\right)$. Figure 11 shows the optimized $(a, b)$ values and the apparent $E_{\mathrm{a}}$ values at various $\alpha$ values obtained by the 
modified Friedman plots applied to the different temperature regions. The variation trends of $(a, b)$ with $\alpha$ are similar in both temperature regions (Figure 11(a) and (b)). The $a$ values initially decrease at $\alpha<0.4$, and subsequently, increase slightly toward the end of the reaction. The $b$ values exhibit wavy fluctuations in both temperature regions, although the magnitude of the fluctuations is not significant. Both $(a, b)$ values for the lower temperature region (Figure 11(a)) is larger than those for the higher temperatures (Figure 11(b)), for which the difference in $b$ values between the different temperature regions is distinguishable. The difference in the variation trends of the apparent

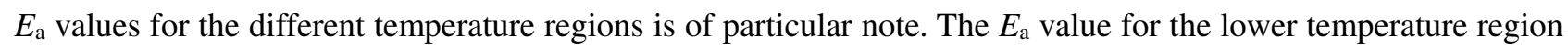
is approximately constant during entirety of the reaction, with the average value of $96.9 \pm 2.5 \mathrm{~kJ} \mathrm{~mol}^{-1}(0.1 \leq \alpha \leq$ $0.9)$. On the other hand, in the higher temperature region, the apparent $E_{\mathrm{a}}$ values initially decrease during the first half of the reaction and approach to the value of the lower temperature region, which is expected based on the changes in the slopes of the modified Friedman plots as the reaction advances (Figure S22). The average $E_{\mathrm{a}}$ value during the second half of the reaction at temperatures above $371 \mathrm{~K}$ is determined to be $115.6 \pm 2.6 \mathrm{~kJ} \mathrm{~mol}^{-1}(0.50 \leq$ $\alpha \leq 0.95$ ). The observed variation in $E_{\mathrm{a}}$ values for the mass-loss process at temperatures above $371 \mathrm{~K}$ indicates a possible change in the mechanistic features of the reaction as the reaction advances (against the assumption of an invariant $f(\alpha)$ form irrespective of the heating and atmospheric conditions being fulfilled). In this case, the exponents $(a, b)$ in the AF play the role of accommodating the changes in the $f(\alpha)$ value in an empirical manner, in addition to accommodating the influence of the $p\left(\mathrm{H}_{2} \mathrm{O}\right)$ value in the kinetic description. Note that the apparent $E_{\text {a }}$ values obtained for this case using the modified Friedman plots do not have a reliable physico-chemical meaning. The modified Friedman plots with the restriction $a=b$ indicate the same trends, except for the $b$ value, as shown in Figures S23 and S24. 

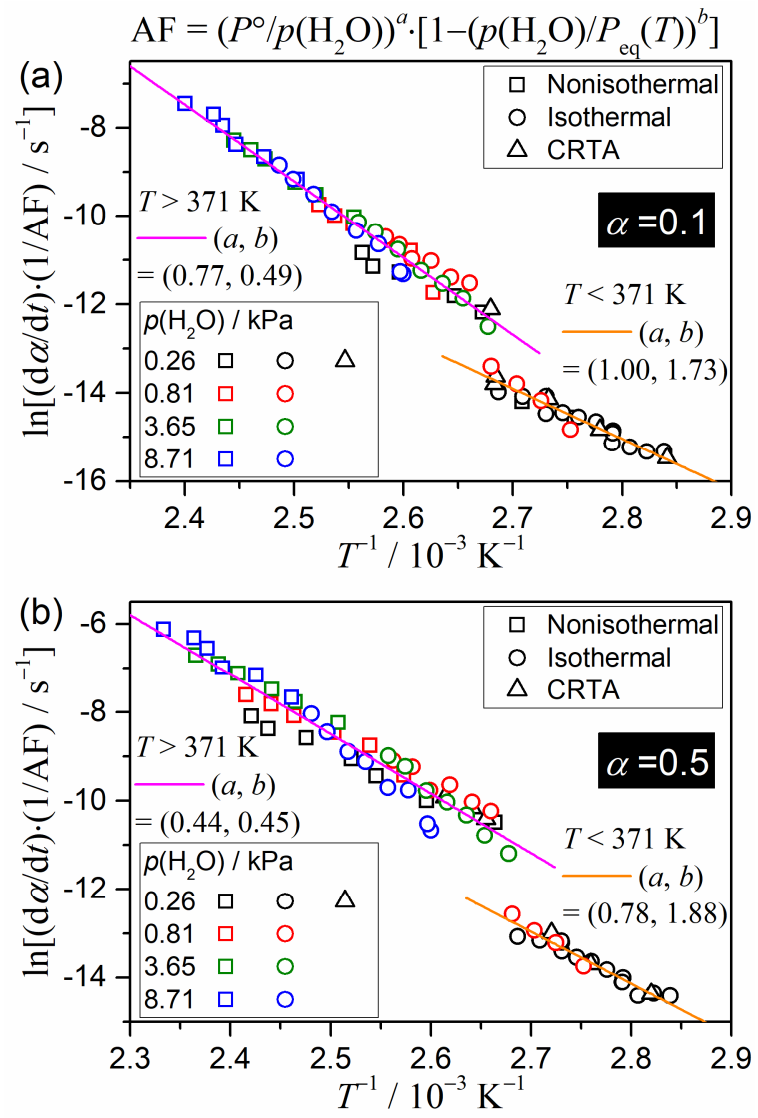

Figure 10. Typical modified Friedman plots with the AF in Eq. (7) $(a \neq b)$ for the mass-loss process of the thermal dehydration of LSM in the separated temperature regions above and below $371 \mathrm{~K}$ : (a) $\alpha=0.1$ and (b) $\alpha=0.5$. 

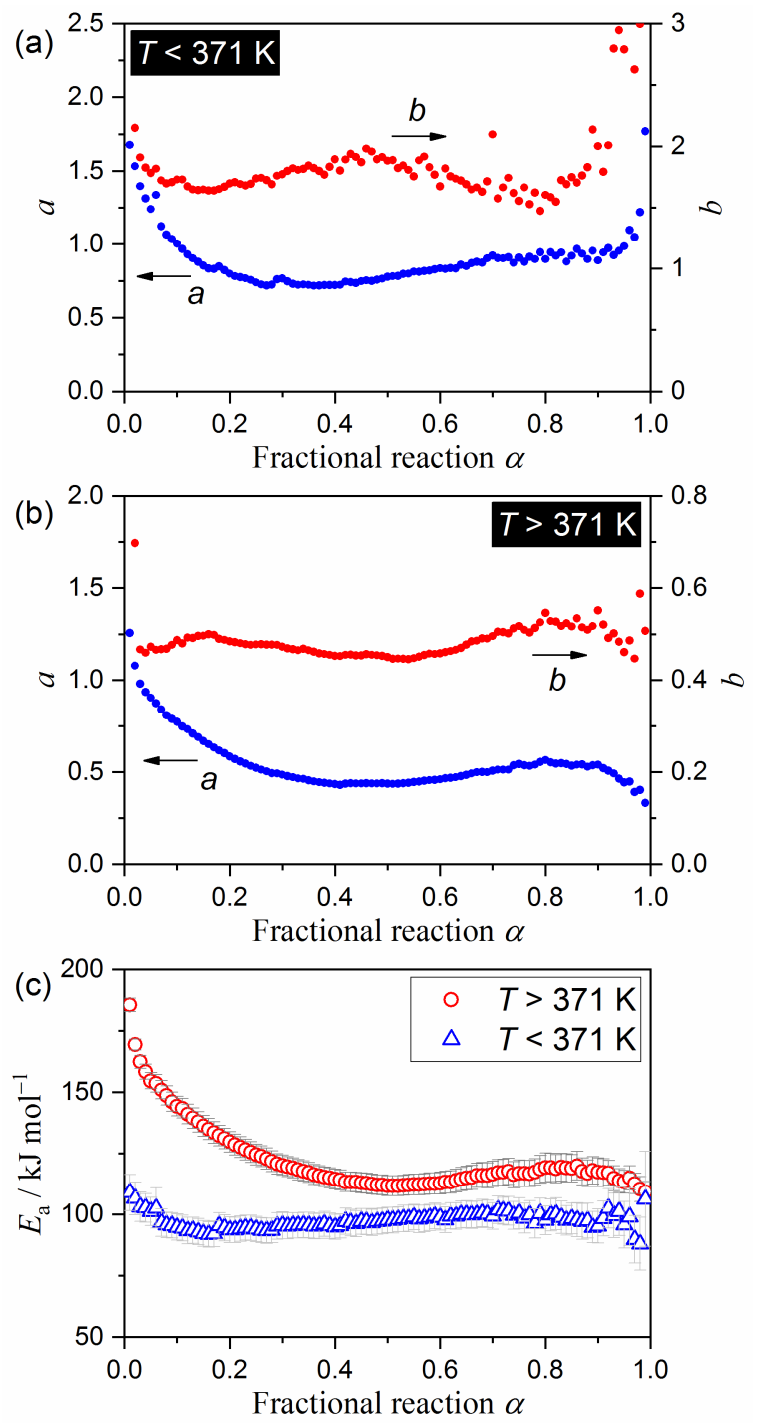

Figure 11. Results of the modified Friedman plots with the AF in Eq. (7) $(a \neq b)$ for the mass-loss process of the thermal dehydration of LSM in the individual temperature regions above and below $371 \mathrm{~K}:$ (a) $(a, b)$ values for the reaction at temperatures below $371 \mathrm{~K}$ at various $\alpha$ values, (b) $(a, b)$ values for the reaction at temperatures above $371 \mathrm{~K}$ at various $\alpha$ values, and (c) comparison of $E_{\mathrm{a}}$ variations with $\alpha$ for the reactions in the two temperature regions.

\subsection{Universal kinetic modeling based on the physico-geometrical consecutive IP-SR-PBR $(n)$ model}

For the mass-loss process of the thermal dehydration of LSM at temperatures above $371 \mathrm{~K}$, a possible change in the mechanistic feature of the reaction with the applied $p\left(\mathrm{H}_{2} \mathrm{O}\right)$ value is expected from the results of the conventional Friedman plot applied without considering the influence of $p\left(\mathrm{H}_{2} \mathrm{O}\right)$. This is, especially true for the different variation trends of the apparent $E_{\mathrm{a}}$ value between the reactions at different $p\left(\mathrm{H}_{2} \mathrm{O}\right)$ values as the reaction advanced (Figure 9(b)). An initial decrease in the $E_{\mathrm{a}}$ value appears when the reaction occurs at $p\left(\mathrm{H}_{2} \mathrm{O}\right)$ values above $0.81 \mathrm{kPa}$, and the $\alpha$ range of the initial $E_{\mathrm{a}}$ decrease is systematically extended with increasing $p\left(\mathrm{H}_{2} \mathrm{O}\right)$ value. Comparing the isothermal mass-loss curves at different $p\left(\mathrm{H}_{2} \mathrm{O}\right)$ values, the sigmoidal shape is more distinguishable for the process at higher $p\left(\mathrm{H}_{2} \mathrm{O}\right)$ values, which is accompanied by the prolongation of the IP. The physico-geometrical consecutive process comprising the initial SR and subsequent PBR, i.e., the Mampel-type model, is a possible explanation for the 
sigmoidal mass-loss behavior. ${ }^{41,42,44,46-48,65,92-97}$ In the scheme of the consecutive SR-PBR model, the variation in the mechanistic feature with the $p\left(\mathrm{H}_{2} \mathrm{O}\right)$ value, as appearing in the sigmoidal shape of the mass-loss curves, is interpreted by the change in the relative contributions of the SR and PBR on the overall kinetics. Thus, a separate characterization of the kinetic behaviors of the SR and PBR for each mass-loss curve recorded under specific temperature and $p\left(\mathrm{H}_{2} \mathrm{O}\right)$ conditions is required to explain the influence of $p\left(\mathrm{H}_{2} \mathrm{O}\right)$ on the kinetics of the mass-loss process. For the thermal dehydration of LSM, the IP is the preliminary process for the subsequent SR-PBR process. The differential kinetic equations for the consecutive IP-SR-PBR model at constant temperature have been derived by Ogasawara and $\mathrm{Koga}^{46}$ by considering different dimensions, $n$, of the shrinkage of the reaction interface during the PBR, as listed in Table S6. These kinetic equations comprise three rate constants for the IP, SR, and PBR $(n)$, which are $k_{\mathrm{IP}}\left(=1 / t_{\mathrm{IP}}\right), k_{\mathrm{SR}}$, and $k_{\mathrm{PBR}(n)}$, respectively. During the kinetic calculation based on the differential kinetic equations of the IP-SR-PBR $(n)$ models, these three rate constants for each isothermal kinetic curve recorded under different temperature and $p\left(\mathrm{H}_{2} \mathrm{O}\right)$ conditions are optimized through fitting via nonlinear least squares analysis to minimize the squares sum of differences between the experimental and calculated data.

$$
F=\sum_{i=1}^{N}\left[\left(\frac{\mathrm{d} \alpha}{\mathrm{d} t}\right)_{\mathrm{exp}, i}-\left(\frac{\mathrm{d} \alpha}{\mathrm{d} t}\right)_{\mathrm{cal}, i}\right]^{2}
$$

where $N$ is the number of data points in a kinetic curve. At the same time, the most appropriate $n$ value for the $\operatorname{PBR}(n)$ is estimated by comparing the determination coefficients $\left(\mathrm{R}^{2}\right)$ of the fittings using the kinetic equations assumed different $n$ values (=1,2, or 3). Before the mathematical optimization run, the initial values of $k_{\mathrm{IP}}$ and $k_{\mathrm{PBR}(n)}$ were calculated from the aforementioned results of formal kinetic calculations for the IP (Figure S9 and Table S2) and overall mass-loss process (Figure 9 and Table S5), which do not consider the influence of $p\left(\mathrm{H}_{2} \mathrm{O}\right)$, respectively. After setting the initial $k_{\mathrm{IP}}$ and $k_{\mathrm{PBR}(n)}$ values, the initial $k_{\mathrm{SR}}$ value was selected by graphically comparing the fitting of the calculated curve to the experimental kinetic curve.

The isothermal mass-loss curves recorded at three different $p\left(\mathrm{H}_{2} \mathrm{O}\right)$ values, i.e., $0.81,3.65$, and 8.63, were subjected to the kinetic calculations based on the IP-SR-PBR $(n)$ models. Figure 12 shows typical fitting results using the kinetic equations with different $n$ values. Irrespective of the $n$ value, a nearly perfect fit is observed for the integral kinetic curves. Comparing the fits to differential kinetic curve, the fits of the kinetic models with $n=2$ and 3 are more satisfactory than that obtained with $n=1$; however, the priority of the kinetic models with $n=2$ or 3 cannot be determined through statistical comparison. The expected interface shrinkage dimension of $n=2$ or 3 is well explained when considering the shape of the LSM crystals used as the sample (Figure S2), which is a hexagonal thick plate, i.e., differing from an ideal cylindrical $(n=2)$ or cubic/spherical $(n=3)$ shape. Similar results were obtained for all isothermal kinetic curves for the thermal dehydration of LSM at various temperatures and under different $p\left(\mathrm{H}_{2} \mathrm{O}\right)$ values larger than $0.81 \mathrm{kPa}$. Tables $\mathrm{S} 7$ and $\mathrm{S} 8$ list the rate constants of $k_{\mathrm{IP}}, k_{\mathrm{SR}}$, and $k_{\mathrm{PBR}(n)}$ optimized based on the IP-SR-PBR(2) and IP-SR-PBR(3) models, respectively. 

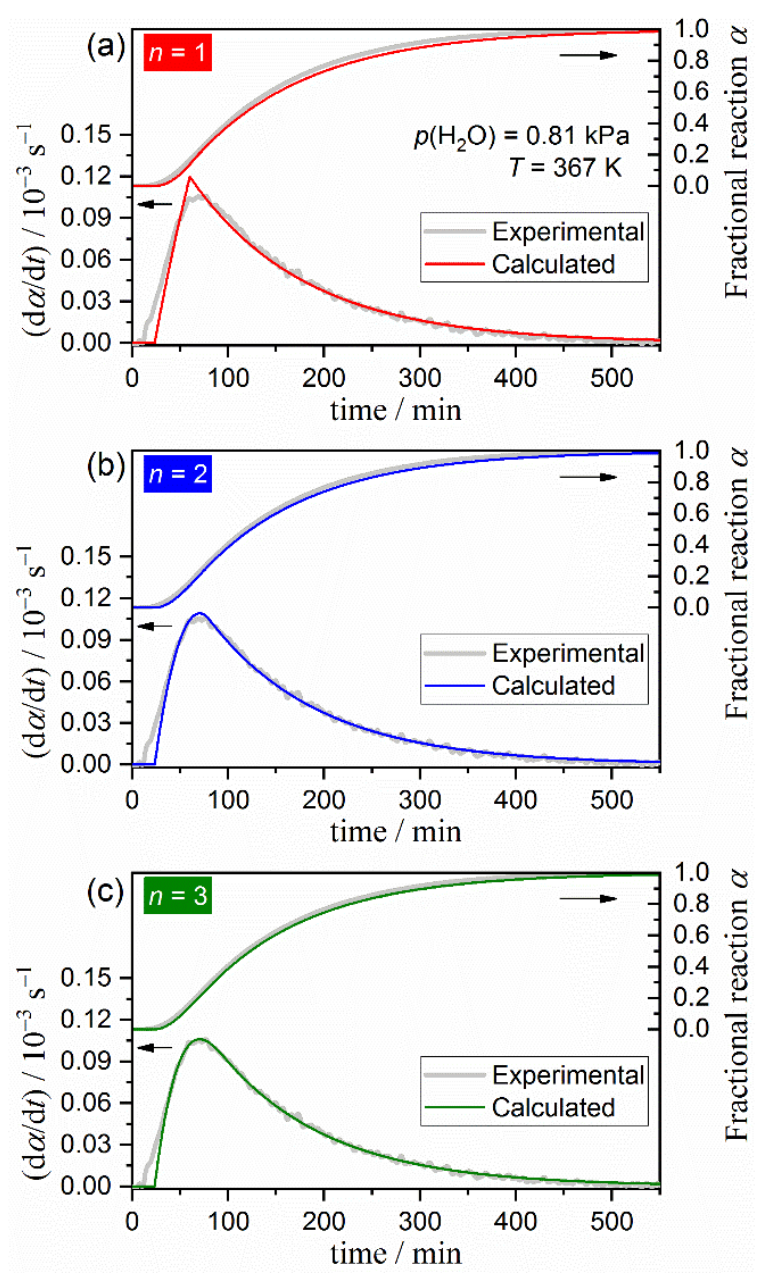

Figure 12. Typical results of the nonlinear least squares analysis for fitting the isothermal kinetic curves for the thermal dehydration of LSM using IP-SR-PBR (n) models: (a) $n=1$, (b) $n=2$, and (c) $n=3$.

As a preliminary examination, the conventional Arrhenius plot was applied to the optimized rate constants at different temperatures without considering the influence of $p\left(\mathrm{H}_{2} \mathrm{O}\right)$ value.

$$
\ln k=\ln A-\frac{E_{\mathrm{a}}}{R T}
$$

Irrespective of the component reaction steps, the individual Arrhenius plots were obtained for the reactions at each $p\left(\mathrm{H}_{2} \mathrm{O}\right)$ value, as shown in Figures $\mathrm{S} 25$ and $\mathrm{S} 26$ for the rate constants optimized on the basis of the IP-SR-PBR(2) and IP-SR-PBR(3) models, respectively. The apparent Arrhenius parameters for each reaction step at each $p\left(\mathrm{H}_{2} \mathrm{O}\right)$ value, determined by the Arrhenius plots shown in Figures S25 and S26, are summarized in Table S9. Irrespective of the reaction step, the apparent $E_{\mathrm{a}}$ value tends to increase with the $p\left(\mathrm{H}_{2} \mathrm{O}\right)$ value, except for the values determined for the SR and PBR(3), where the largest value is observed at $p\left(\mathrm{H}_{2} \mathrm{O}\right)=3.64 \mathrm{kPa}$. Introduction of the AF concerning the $p\left(\mathrm{H}_{2} \mathrm{O}\right)$ value is again necessary for the universal kinetic description in each physico-geometrical reaction step of the thermal dehydration of LSM: ${ }^{58-59}$

$$
k=A \exp \left(-\frac{E_{\mathrm{a}}}{R T}\right) f(\alpha) \cdot a\left(p\left(\mathrm{H}_{2} \mathrm{O}\right), P_{\mathrm{eq}}(T)\right)
$$

Thus, 


$$
\ln \left[\frac{k}{a\left(p\left(\mathrm{H}_{2} \mathrm{O}\right), P_{\mathrm{eq}}(T)\right)}\right]=\ln A-\frac{E_{\mathrm{a}}}{R T}
$$

The analytical form of the AF in Eq. (7) is applicable for modifying the Arrhenius plots. When the exponents $(a, b)$ in Eq. (7) was set to be $(0,1)$ in line with the conventional AF, no distinguishable improvement of the Arrhenius plots were observed, as shown in Figures S27 and S28 for the rate constants optimized on the basis of the IP-SRPBR(2) and IP-SR-PBR(3) models, respectively. The apparent Arrhenius parameters for each reaction step at each $p\left(\mathrm{H}_{2} \mathrm{O}\right)$ value, determined by the modified Arrhenius plots shown in Figures $\mathrm{S} 27$ and $\mathrm{S} 28$, are summarized in Table S10. Figure 13 shows the modified Arrhenius plots with the AF in Eq. (7) for each reaction step examined under the condition of $a \neq b$ for the rate constants optimized on the basis of the IP-SR-PBR(2) model. The counterpart results determined with the restriction of $a=b$ are shown in Figure S29. In both cases, the modified Arrhenius plots for each reaction step exhibit a statistically significant single linear correlation for the data points over different temperature and $p\left(\mathrm{H}_{2} \mathrm{O}\right)$ conditions. The same is observed for the rate constants optimized based on the IP-SRPBR(3) model as shown in Figures S30 and S31 for the cases with and without the restriction of $a=b$, respectively. Table 4 lists the kinetic parameters determined through the modified Arrhenius plots with the AF in Eq. (7). When the modified Arrhenius plots are applied without restricting the $(a, b)$ values, slightly improved linear correlations of the Arrhenius plots are obtained in all reaction steps as compared to those with the restriction of $a=b$, although the differences are negligible. Comparing the $(a, b)$ values optimized with and without the restriction of $a=b$, the change in the $a$ value is apparently smaller than that in the $b$ value. This implies that, with the restriction of $a=b$, the $b$ value is exerted by the $a$ value. The resulting Arrhenius parameters obtained with and without the restriction of $a=b$ are comparable, within the standard error of each parameter. Therefore, it is likely that the $a$ value plays an important role in realizing the universal kinetic description of each reaction step over different temperature and $p\left(\mathrm{H}_{2} \mathrm{O}\right)$ conditions. As shown in Figure $\mathrm{S} 13$, the applied $p\left(\mathrm{H}_{2} \mathrm{O}\right)$ value is much smaller than the $P_{\text {eq }}(T)$ value in the actual temperature range of the reaction; therefore, the value of $p\left(\mathrm{H}_{2} \mathrm{O}\right) / P_{\mathrm{eq}}(T)$ takes a small value and the second part of the AF in Eq. (7) has limited contribution. Even so, because a smaller $b$ value is optimized in all reaction steps under the condition of $a \neq b$, the contribution of the second part of the AF slightly increases in comparison with that under the condition of $a=b$. Comparing the Arrhenius parameters determined based on the IP-SR-PBR(2) and IP-SR-PBR(3) models, those for the $\operatorname{PBR}(n)$ steps exhibit significant differences, i.e., the apparent Arrhenius parameters for PBR(3) are larger than those for PBR(2), whereas those for the IP and SR steps are comparable. Thus, determination of the shrinkage dimension $n$ for the PBR is necessary for a more exact description of the kinetic behavior. However, the actual shrinkage dimension of the reaction interface may not be the integral dimension. The shape of the original single crystals is neither cylinder nor spherical/cubic. The linear advancement rate of the reaction interface may depend on the crystallographic direction. The reaction interface may not be a smooth plane. Thus, as has been reported in many previous articles, ${ }^{98-100}$ a non-integral or fractal dimension for the reaction interface shrinkage with a value between 2 and 3 is expected for the thermal dehydration of LSM. 
(a)
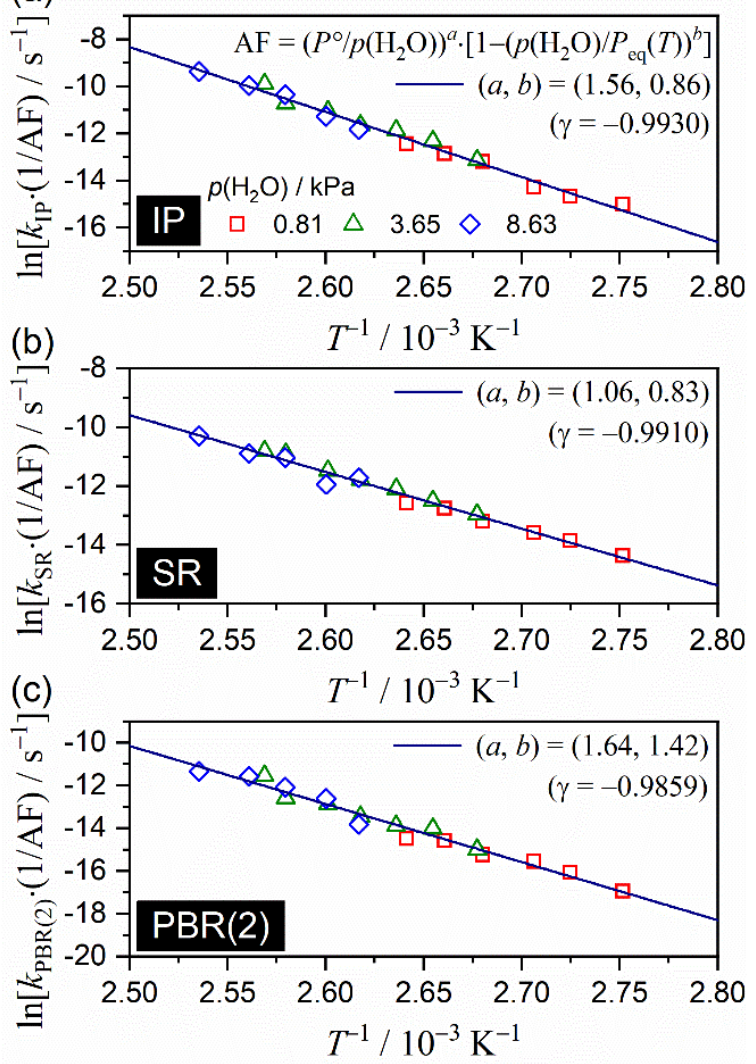

Figure 13. Modified Arrhenius plots using the AF in Eq. (7) without any restrictions for $a$ and $b$ applied to the rate constants for the respective reaction steps over different $p\left(\mathrm{H}_{2} \mathrm{O}\right)$ values, optimized on the basis of the IP-SR-PBR(2) model: (a) IP, (b) SR, and (c) PBR(2).

Table 4. Arrhenius parameters for describing the kinetics of respective reaction steps over different temperatures and $p\left(\mathrm{H}_{2} \mathrm{O}\right)$ values.

\begin{tabular}{|c|c|c|c|c|c|c|c|}
\hline \multirow{2}{*}{ Condition } & \multirow{2}{*}{ Model } & \multirow{2}{*}{$\begin{array}{c}\text { Reaction } \\
\text { step }\end{array}$} & \multicolumn{2}{|c|}{ Exponents } & \multirow{2}{*}{$E_{\mathrm{a}} / \mathrm{kJ} \mathrm{mol}^{-1}$} & \multirow{2}{*}{$\ln \left(A / \mathrm{s}^{-1}\right)$} & \multirow{2}{*}{$-\gamma^{\mathrm{a}}$} \\
\hline & & & $\bar{a}$ & $\bar{b}$ & & & \\
\hline \multirow[t]{6}{*}{$a=b$} & IP-SR-PBR(2) & IP & 1.65 & 1.65 & $235.4 \pm 7.2$ & $62.1 \pm 2.3$ & 0.9928 \\
\hline & & SR & 1.10 & 1.10 & $163.1 \pm 5.6$ & $39.2 \pm 1.8$ & 0.9909 \\
\hline & & $\operatorname{PBR}(2)$ & 1.66 & 1.66 & $226.9 \pm 9.7$ & $58.0 \pm 3.1$ & 0.9858 \\
\hline & IP-SR-PBR(3) & IP & 1.65 & 1.65 & $235.4 \pm 7.2$ & $62.1 \pm 2.3$ & 0.9928 \\
\hline & & SR & 1.07 & 1.07 & $158.5 \pm 5.6$ & $37.9 \pm 1.8$ & 0.9903 \\
\hline & & PBR(3) & 1.90 & 1.90 & $264.6 \pm 14.0$ & $68.9 \pm 4.5$ & 0.9783 \\
\hline \multirow[t]{6}{*}{$a \neq b$} & IP-SR-PBR(2) & IP & 1.56 & 0.86 & $229.9 \pm 6.9$ & $60.8 \pm 2.2$ & 0.9930 \\
\hline & & SR & 1.06 & 0.83 & $160.4 \pm 5.4$ & $38.7 \pm 1.8$ & 0.9910 \\
\hline & & $\operatorname{PBR}(2)$ & 1.64 & 1.42 & $225.9 \pm 9.6$ & $57.8 \pm 3.1$ & 0.9859 \\
\hline & IP-SR-PBR(3) & IP & 1.56 & 0.86 & $229.9 \pm 6.9$ & $60.8 \pm 2.2$ & 0.9930 \\
\hline & & SR & 1.07 & 1.06 & $158.4 \pm 5.6$ & $37.9 \pm 1.8$ & 0.9903 \\
\hline & & PBR(3) & 1.86 & 1.29 & $262.0 \pm 13.9$ & $68.2 \pm 4.4$ & 0.9784 \\
\hline
\end{tabular}


${ }^{a}$ Correlation coefficient of the linear regression analysis.

\subsection{Interpretation of the kinetic behavior and significance of the universal kinetic approach}

As demonstrated above, the introduction of the AF presented in Eq. (7) enables kinetic descriptions of the thermal dehydration of LSM over different temperature and $p\left(\mathrm{H}_{2} \mathrm{O}\right)$ conditions in both the component IP and mass-loss process. Compared to the conventional kinetic analysis performed without considering the effect of $p\left(\mathrm{H}_{2} \mathrm{O}\right)$, the results of the universal kinetic characterization provide additional information on the kinetic behavior of the reaction.

The change in the kinetic behavior observed at approximately the boiling point of water in both the IP and initial stage of the mass-loss process (Figures 7, S18, and S20) is an important characteristic of the thermal dehydration of LSM. If the possible condensation of water vapor generated by the reaction is considered for the reactions at a temperature lower than the boiling point, the contribution of the condensed water to the elementary surface process of water molecular desorption is considered a possible cause of the phenomenon observed in both the IP and SR processes. In the mass-loss process, this phenomenon is observed as the bending of the Friedmantype plots in the first half of the overall process (Figures S18 and S20). This is illustrated through the change in the apparent $E_{\mathrm{a}}$ value and $a$ value in the $\mathrm{AF}$ evaluated by the modified Friedman plots, where the kinetic behavior of the reaction at higher temperatures $(T>371 \mathrm{~K})$ gradually approaches that of the reaction at lower temperatures $(T$ $<371 \mathrm{~K})$ (Figures 11 and S24) as the mass-loss process advances. If the condensation of water vapor is the possible cause of change in the kinetic behavior of the reaction at the higher temperatures as the reaction advances, the contribution of the condensation/evaporation of water during the elementary step of diffusional removal through the surface product layer should also be considered for the reaction at lower temperatures and for the second half of the reaction at higher temperatures. The diffusion length of the water vapor from the internal reaction interface to the surface of the reacting particle increases as the reaction advances. Under a postulated high pressure in the diffusion path, condensation/evaporation of water vapor is a provable phenomenon.

Comparisons of the results obtained by the universal kinetic approaches based on the formal isoconversional method and the physico-geometrical reaction models provide further insight into the kinetic characteristics of the reaction. For the IP, the results of the modified Arrhenius plots with the AF based on (i) the formal procedure (Table 2) for the process at temperatures higher than $371 \mathrm{~K}$ (Table 4) and (ii) the IP-SR-PBR $(n)$ model for the process at higher $p\left(\mathrm{H}_{2} \mathrm{O}\right)$ values $\left(p\left(\mathrm{H}_{2} \mathrm{O}\right) \geq 0.81 \mathrm{kPa}\right)$ are comparable, exhibiting similar magnitude relation among the $(a, b), E_{\mathrm{a}}$, and $A$ values, although some differences in the value of each kinetic parameter are evident because of the slightly different temperature and $p\left(\mathrm{H}_{2} \mathrm{O}\right)$ ranges of the kinetic data subjected to these kinetic calculations. On the other hand, for the mass-loss process, the results of the universal kinetic analyses based on (i) the modified isoconversional method with the $\mathrm{AF}(T>371 \mathrm{~K}$, Figure 11) and (ii) the modified Arrhenius plots with AF for each physico-geometrical reaction step of IP-SR-PBR $(n)$ model $\left(p\left(\mathrm{H}_{2} \mathrm{O}\right) \geq 0.81 \mathrm{kPa}\right.$, Table 4$)$ indicate significant contradictions. In the isoconversional kinetic approach, gradual decreases in $a$ and $E_{\text {a }}$ values during the first half of the overall mass-loss process are observed, followed by nearly constant values of $a$ and $E_{\mathrm{a}}$ in the second half of the reaction. Whereas, the $b$ values in the AF are approximately constant during the overall mass-loss process. In contrast, in the results based on the IP-SR-PBR $(n)$ model, all $(a, b), E_{\mathrm{a}}$, and $A$ values increase as the mass-loss process proceeds from the primary SR to the subsequent PBR.

In this situation, the applicability of the universal kinetic analysis based on the isoconversional plots 
should be reconsidered with respect to a preliminary requisite, i.e., the invariance of $f(\alpha)$ among the kinetic data subjected to the kinetic calculation. This prerequisite is not always fulfilled in the isoconversional kinetic approach to the kinetic data of the thermal decomposition of solids recorded under different heating conditions, resulting in apparent variations in the calculated $E_{\mathrm{a}}$ value as the reaction advances. When the kinetic data recorded under different heating and atmospheric conditions are subjected to the universal kinetic description, as in the present study, changes in the physico-geometrical reaction mechanism, as expressed by $f(\alpha)$, may be more probable because of a wider range of reaction conditions covered by the series of kinetic data. The thermal dehydration of LSM is one such example, where the physico-geometrical reaction mechanism changes with the heating and $p\left(\mathrm{H}_{2} \mathrm{O}\right)$ conditions. The mechanistic change can be expected from the change in the apparent shape of the isothermal massloss curves. Besides the prolongation of the IP, the sigmoidal shape of the isothermal mass-loss curve becomes more apparent with increasing $p\left(\mathrm{H}_{2} \mathrm{O}\right)$ value (Figures 1 and 5). Because the mass-loss process is composed of the SR and PBR occurring consecutively and with a distribution of the fractional reactions of each single crystalline particle in the sample matrix (Figures 3 and 4), the change in the shape of the isothermal mass-loss curve is interpreted as resulting from the variation in the contribution range of the SR in the overall $\alpha$ owing to the effect of the atmospheric $p\left(\mathrm{H}_{2} \mathrm{O}\right)$ value. This trend appears in the results of the conventional Friedman plot applied to the kinetic data at each $p\left(\mathrm{H}_{2} \mathrm{O}\right)$ value as the variation of the $\alpha$ range for the initial decrease in the $E_{\mathrm{a}}$ value. Even for such a case, the modified Friedman plots with the AF in Eq. (7) exhibit statistically significant linear correlations among the data points recorded under different heating and $p\left(\mathrm{H}_{2} \mathrm{O}\right)$ conditions (Figures 10, S18, S20, S22, and S23). When the mechanistic change depending on the $p\left(\mathrm{H}_{2} \mathrm{O}\right)$ value is apparent, the exponents $(a, b)$ in the $\mathrm{AF}$ also accommodate the variation of $f(\alpha)$, besides the effect of the $p\left(\mathrm{H}_{2} \mathrm{O}\right)$ value on the reaction rate. Thus, the obtained exponents $(a, b)$ and $E_{\mathrm{a}}$ values should be considered as superficial values with limited physico-chemical meaning.

A decrease in the $E_{\mathrm{a}}$ value in the initial stage of the thermal dehydration of LSM, determined by the isoconversional method, has been reported in some previous studies. The variation trend itself is understood as an empirical indication of the change in the physico-geometrical reaction mechanism from the SR by the nucleation and growth to the PBR by the shrinkage of the reaction interface as the mass-loss process advances. In the kinetic approach based on the IP-SR-PBR $(n)$ model, the rate constants for each reaction step are determined for each isothermal kinetic curve recorded under specific temperature and $p\left(\mathrm{H}_{2} \mathrm{O}\right)$ conditions as the initial step of the kinetic calculation. Through this calculation procedure, the kinetic information for each reaction step is separately extracted from the overall kinetic curve. If this kinetic calculation step is successful, the subsequent kinetic calculation step of the simultaneous evaluations of the temperature and $p\left(\mathrm{H}_{2} \mathrm{O}\right)$ dependences through the modified Arrhenius plots can be performed without considering the changes in the overall reaction mechanism caused by the variations in heating and atmospheric conditions.

It is highly likely that the results of the universal kinetic analysis based on the $\operatorname{IP}-\operatorname{SR}-\operatorname{PBR}(n)$ model provide information on (i) kinetic behavior of each reaction step over different temperature and $p\left(\mathrm{H}_{2} \mathrm{O}\right)$ conditions and (ii) variations in the kinetic behavior as the reaction steps advance. The magnitude relation between the exponents $(a, b)$ in each reaction step may characterize the type of effect that atmospheric water vapor has on the kinetics. The variations in the $(a, b), E_{\mathrm{a}}$, and $A$ values as the consecutive reaction steps advance may account for the characteristics of the overall consecutive process. To achieve such an advanced state of kinetic characterization of the thermal decomposition of solids, sufficient examples of the kinetic results obtained by the proposed kinetic 
approach for a series of reactions are necessary to establish a classification for the different types of kinetic behavior. The magnitude relations between exponents $(a, b)$ in each reaction step and the variations in the Arrhenius parameters observed for the thermal dehydration of LSM should be interpreted as an example. However, the present study clearly indicates that the thermal dehydration of crystalline hydrates provides suitable model reactions for challenging the advanced kinetic understanding via the universal kinetic approach over different temperatures and partial pressures of the product gas, as well as for the thermal decomposition of metal hydroxides reported previously. ${ }^{58-59}$

\section{Conclusions}

The thermal dehydration of LSM exhibits specific kinetic behaviors in the presence of atmospheric water vapor. The reaction is accompanied by the distinguishable IP, which is prolonged with increasing $p\left(\mathrm{H}_{2} \mathrm{O}\right)$ values at a constant temperature and with decreasing temperature at a constant $p\left(\mathrm{H}_{2} \mathrm{O}\right)$ value. The subsequent mass-loss process is also retarded by atmospheric water vapor, which is typically seen as the prolongation of the overall reaction time at a constant temperature and the shift of the reaction temperature region to higher values under linear heating at a given $\beta$ value with an increasing $p\left(\mathrm{H}_{2} \mathrm{O}\right)$ value. All these behaviors are explained by the reversible feature of the reaction. Under isothermal conditions, a typical sigmoidal feature is observed for the mass-loss curves, which is further enhanced at increasing $p\left(\mathrm{H}_{2} \mathrm{O}\right)$ values. The mass-loss process is physico-geometrically characterized by the consecutive SR and subsequent PBR, as supported by microscopic evidence. In a sample matrix of single crystalline LSM particles, distributions of the reaction initiation time, and thus, the fractional reaction of each reacting particle in the sample matrix are also evidenced. To account for the kinetic behavior over different $p\left(\mathrm{H}_{2} \mathrm{O}\right)$ values, Eq. (7) is derived as an analytical form of the $\mathrm{AF}$ to be introduced into the conventional kinetic equation.

The modified kinetic equation with the AF was successfully applied to both the IP and mass-loss process over different temperature and $p\left(\mathrm{H}_{2} \mathrm{O}\right)$ conditions, realizing a universal kinetic description. Formal kinetic analyses using the modified kinetic equation revealed changes in the kinetic behavior for both the IP and mass-loss process at approximately $371 \mathrm{~K}$, from which possible contributions of the condensation/evaporation of the evolved water vapor in some elementary steps were expected for the reaction at lower temperatures $(T<371 \mathrm{~K})$. During the secondhalf of the mass-loss process, the kinetic behavior over the entire temperature region examined was universally described, owing to the gradual variation of the kinetic behavior at the higher temperature region to that at the lower temperature region. A contribution of the condensation/evaporation of the evolved gas was also expected in the second half of the reaction over the entire temperature region examined.

Furthermore, each isothermal kinetic curve recorded at a specific temperature and $p\left(\mathrm{H}_{2} \mathrm{O}\right)$ value was analyzed by applying the physico-geometrical consecutive reaction model (IP-SR-PBR $(n)$ model), through which the IP-SR-PBR(2) or IP-SR-PBR(3) model was selected as the most appropriate kinetic model and the rate constants for each physico-geometrical reaction step were determined simultaneously. In each reaction step, the rate constants for the reactions under different temperature and $p\left(\mathrm{H}_{2} \mathrm{O}\right)$ conditions were universally described by a single Arrhenius-type plot based on the modified kinetic equation with the AF. The determined kinetic parameters, including the exponents $(a, b)$ and the $E_{\mathrm{a}}$, and $A$ values, in the respective reaction steps were compared in view of the magnitude relation between the kinetic parameters in each reaction step and the variation in each kinetic parameter as the reaction step advanced. The predominant role of exponent $a$ in the AF for the universal description 
over different temperature and $p\left(\mathrm{H}_{2} \mathrm{O}\right)$ values in all reaction steps was revealed as a characteristic of the present reaction. The magnitude relations of all kinetic parameters among those for different reaction steps with PBR $\geq$ IP $>$ SR were also identified as kinetic features of the reaction.

This study demonstrated that the kinetic feature of the thermal dehydration of LSM is universally described over different temperature and $p\left(\mathrm{H}_{2} \mathrm{O}\right)$ values. The kinetic results provide further insight into the nature of the reaction, i.e., beyond those obtained by the conventional kinetic analysis under a specific reaction condition. However, to highlight the true value of the universal kinetic approach, sufficient examples of the universal kinetic results for a series of reactions with various specific features are required. One such series of reactions is the thermal dehydration of crystalline hydrates.

\section{Footnotes}

Electronic Supplementary Information

Electronic supplementary information (ESI) is available: S1. Literature Survey (Table S1, Figure S1); S2. Sample Characterization (Figures S2-S6); S3. Instrumental (Figures S7 and S8); S4. Formal Kinetic Analysis of the Induction Period (Figures S9-S13, Tables S2-S4); S5. Formal Kinetic Analysis for the Mass-Loss Process (Figures S14-S24, Tables S5); S6. Kinetic Analysis Based on the Physico-Geometrical Consecutive Reaction Model (Tables S6-S10, Figures S25-S31).

\section{Corresponding Author}

*Tel./fax: +81-82-424-7092. E-mail: nkoga@ hiroshima-u.ac.jp

\section{Acknowledgements}

The present work was supported by JSPS KAKENHI Grant Numbers 17H00820.

\section{References}

1. Young, D. A., Decomposition of Solids; Pergamon: Oxford, 1966; Vol. 1.

2. Brown, M. E.; Dollimore, D.; Galwey, A. K., Reactions in the Solid State; Elsevier: Amsterdam, 1980 ; Vol. 22.

3. Galwey, A. K.; Brown, M. E., Thermal Decomposition of Ionic Solids; Elsevier: Amsterdam, 1999.

4. Galwey, A. K., Structure and Order in Thermal Dehydrations of Crystalline Solids. Thermochim. Acta 2000, 355 , $181-238$.

5. Koga, N.; Tanaka, H., A Physico-Geometric Approach to the Kinetics of Solid-State Reactions As Exemplified by the Thermal Dehydration and Decomposition of Inorganic Solids. Thermochim. Acta 2002, 388, 41-61.

6. Koga, N., Ozawa's Kinetic Method for Analyzing Thermoanalytical Curves. J. Therm. Anal. Calorim. 2013, 113, 1527-1541.

7. Koga, N.; Šesták, J.; Simon, P., Some Fundamental and Historical Aspects of Phenomenological Kinetics in the Solid State Studied by Thermal Analysis. In Thermal analysis of Micro, Nano- and Non-Crystalline Materials, Šesták, J.; Simon, P., Eds. Springer: 2013; pp 1-28.

8. Koga, N., Physico-Geometric Approach to the Kinetics of Overlapping Solid-State Reactions. In Handbook of Thermal Analysis and Calorimetry, 2nd ed.; Vyazovkin, S.; Koga, N.; Schick, C., Eds. Elsevier: Amsterdam, 2018 ; Vol. 6, pp 213-251.

9. Brown, M.; Flynn, R. M.; Flynn, J. H., Report on the ICTAC-Kinetics-Committee (August 1992 to September 1994). Thermochim. Acta 1995, 256, 477-483.

10. Okhotnikov, V. B.; Yakobson, B. I.; Lyakhov, N. Z., Kinetics of Thermal Dehydration of $\mathrm{Li}_{2} \mathrm{SO}_{4} \cdot \mathrm{H}_{2} \mathrm{O}$. React. Kinet. Catal. Lett. 1983, 23, 125-130.

11. Okhotnikov, V. B.; Lyakhov, N. Z., Some New Data Concerning the Interface Chemistry of Dehydration Reactions. Thermochim. Acta 1985, 92, 681-683.

12. Gaponov, Y. A.; Kidyarov, B. I.; Kirdyashkina, N. A.; Lyakhov, N. Z.; Okhotnikov, V. B., Comparative Study of 
Single-Crystal Dehydration of $\mathrm{LiCOOH} \cdot \mathrm{H}_{2} \mathrm{O}$ and $\mathrm{Li}_{2} \mathrm{SO}_{4} \cdot \mathrm{H}_{2} \mathrm{O}$. J Therm Anal 1988, 33, 547-551.

13. Kirdyashkina, N. A.; Okhotnikov, V. B., Kinetic Studies of Isothermal Dehydration of Compressed $\mathrm{Li}_{2} \mathrm{SO}_{4} \cdot \mathrm{H}_{2} \mathrm{O}$

Powders. React. Kinet. Catal. Lett. 1988, 36, 417-422.

14. Tanaka, H., Kinetics and Mechanism of Thermal Dehydration of Lithium Sulfate Monohydrate by Means of TG and DSC. Thermochim. Acta 1982, 52, 195-199.

15. Koga, N.; Tanaka, H., Kinetics and Mechanisms of The Thermal Dehydration of Dilithium Sulfate Monohydrate. J. Phys. Chem. 1989, 93, 7793-7798.

16. Galwey, A. K.; Koga, N.; Tanaka, H., A Kinetic and Microscopic Investigation of the Thermal Dehydration of Lithium Sulphate Monohydrate. J. Chem. Soc. Faraday Trans. 1990, 86, 531.

17. Tanaka, H.; Koga, N., Self-Cooling Effect on the Kinetics of Nonisothermal Dehydration of Lithium Sulfate Monohydrate. J Therm Anal 1990, 36, 2601-2610.

18. Huang, J.; Gallagher, P. K., Influence of Water Vapor on the Thermal Dehydration of $\mathrm{Li}_{2} \mathrm{SO}_{4} \cdot \mathrm{H}_{2} \mathrm{O}$. Thermochim. Acta 1991, 192, 35-45.

19. Koga, N.; Tanaka, H., Conventional Kinetic Analysis of the Thermogravimetric Curves for the Thermal Decomposition of a Solid. Thermochim. Acta 1991, 183, 125-136.

20. Brown, M. E.; Galwey, A. K.; Po, A. L. W., Reliability of Kinetic Measurements for the Thermal Dehydration of Lithium Sulphate Monohydrate: Part 1. Isothermal Measurements of Pressure of Evolved Water Vapour. Thermochim. Acta 1992, 203, 221-240.

21. Brown, M. E.; Galwey, A. K.; Po, A. L. W., Reliability of Kinetic Measurements for the Thermal Dehydration of Lithium Sulphate Monohydrate. Thermochim. Acta 1993, 220, 131-150.

22. Tanaka, H.; Koga, N.; Šesták, J., Thermoanalytical Kinetics for Solid State Reactions as Exemplified by the Thermal Dehydration of $\mathrm{Li}_{2} \mathrm{SO}_{4} \cdot \mathrm{H}_{2} \mathrm{O}$. Thermochim. Acta 1992, 203, 203-220.

23. Epple, M.; Cammenga, H., The Dehydration of Lithium Sulphate Monohydrate Investigated with DSC, TG and Temperature-Resolved X-Ray Diffractometry - A Comparison between Three Methods. Solid State Ionics 1993, 63-65, 307-311.

24. Koga, N.; Tanaka, H., Effect of Sample Mass on the Kinetics of Thermal Decomposition of a Solid. II. Isothermal Dehydration of $\mathrm{Li}_{2} \mathrm{SO}_{4} \cdot \mathrm{H}_{2} \mathrm{O}$. J Therm Anal 1993, 40, 1173-1179.

25. Masud, Y.; Takeuchi, H.; Yahata, A., Kinetics of the Isothermal Dehydration of $\mathrm{Li}_{2} \mathrm{SO}_{4} \cdot \mathrm{H}_{2} \mathrm{O}$ in $\mathrm{Vacuo}$ Thermochim. Acta 1993, 228, 191-196.

26. Rouquerol, F.; Laureiro, Y.; Rouquerol, J., Influence of Water Vapour Pressure on the Thermal Dehydration of Lithium Sulphate Monohydrate. Solid State Ionics 1993, 63-65, 363-366.

27. Koga, N.; Tanaka, H., A Kinetic Compensation Effect Established for the Thermal Decomposition of a Solid. $J$ Therm Anal 1991, 37, 347-363.

28. Koga, N.; Šesták, J., Kinetic Compensation Effect as a Mathematical Consequence of the Exponential Rate Constant. Thermochim. Acta 1991, 182, 201-208.

29. Koga, N.; Šesták, J., Further Aspects of the Kinetic Compensation Effect. J Therm Anal 1991, 37, 1103-1108.

30. Koga, N., A Review of the Mutual Dependence of Arrhenius Parameters Evaluated by the Thermoanalytical Study of Solid-State Reactions: The Kinetic Compensation Effect. Thermochim. Acta 1994, 244, 1-20.

31. Galwey, A. K.; Mortimer, M., Compensation Effects and Compensation Defects in Kinetic and Mechanistic Interpretations of Heterogeneous Chemical Reactions. Int. J. Chem. Kinet. 2006, 38, 464-473.

32. Barrie, P. J., The Mathematical Origins of the Kinetic Compensation Effect: 1. The Effect of Random Experimental Errors. Phys. Chem. Chem. Phys. 2012, 14, 318-326.

33. Barrie, P. J., The Mathematical Origins of the Kinetic Compensation Effect: 2. The Effect of Systematic Errors. Phys. Chem. Chem. Phys. 2012, 14, 327-336.

34. Xu, D.; Chai, M.; Dong, Z.; Rahman, M. M.; Yu, X.; Cai, J., Kinetic Compensation Effect in Logistic Distributed Activation Energy Model for Lignocellulosic Biomass Pyrolysis. Bioresour. Technol. 2018, 265, 139-145.

35. Simakova, N. A.; Lyakhov, N. Z.; Rudina, N. A., Thermal Dehydration of Lithium Sulfate Monohydrate. The Reaction Reversibility and the Solid Product Morphology. Thermochim. Acta 1995, 256, 381-389.

36. Tanaka, H.; Koga, N.; Galwey, A. K., Thermal Dehydration of Crystalline Hydrates: Microscopic Studies and Introductory Experiments to the Kinetics of Solid-State Reactions. Journal of Chemical Education 1995, 72, 251-256.

37. Johnson, W. A.; Mehl, K. F., Reaction Kinetics in Processes of Nucleation and Growth. Trans. Am. Inst. Min. Metall. Eng. 1939, 135, 416-458.

38. Avrami, M., Kinetics of Phase Change. I. General theory. J. Chem. Phys. 1939, 7, 1103-1112.

39. Avrami, M., Kinetics of Phase Change. II. Transformation-Time Relations for Random Distribution of Nuclei. J. Chem. Phys. 1940, 8, 212-223.

40. Avrami, M., Kinetics of Phase Change. III. Granulation, Phase Change, and Microstructure. J. Chem. Phys. 1941, 9, 177-184.

41. Valdivieso, F.; Bouineau, V.; Pijolat, M.; Soustelle, M., Kinetic Study of the Dehydration of Lithium Sulphate Monohydrate. Solid State Ionics 1997, 101, 1299-1303.

42. Favergeon, L.; Pijolat, M.; Valdivieso, F.; Helbert, C., Experimental Study and Monte-Carlo Simulation of the Nucleation and Growth Processes during the Dehydration of $\mathrm{Li}_{2} \mathrm{SO}_{4} \cdot \mathrm{H}_{2} \mathrm{O}$ Single Crystals. Phys. Chem. Chem. Phys. 2005, 7, 3723-3727. 
43. Favergeon, L.; Pijolat, M.; Helbert, C., A Mechanism of Nucleation during Thermal Decomposition of Solids. J. Mater. Sci. 2008, 43, 4675-4683.

44. Mampel, K. L., Time Conversion Formulas for Heterogeneous Reactions at the Phase Boundaries of Solid Bodies, I: The Development of the Mathematical Method and the Derivation of Area Conversion Formulas. Z. Phys. Chem. Abt. A 1940, 187, 43-57

45. Favergeon, L.; Pijolat, M.; Soustelle, M., Surface Nucleation and Anisotropic Growth Models for Solid-State Reactions. Thermochim. Acta 2017, 654, 18-27.

46. Ogasawara, H.; Koga, N., Kinetic Modeling for Thermal Dehydration of Ferrous Oxalate Dihydrate Polymorphs: A Combined Model for Induction Period-Surface Reaction-Phase Boundary Reaction. J. Phys. Chem. A 2014, 118, 24012412.

47. Lan, S.; Zondag, H.; van Steenhoven, A.; Rindt, C., Kinetic Study of the Dehydration Reaction of Lithium Sulfate Monohydrate Crystals Using Microscopy and Modeling. Thermochim. Acta 2015, 621, 44-55.

48. Lan, S.; Zondag, H.; van Steenhoven, A.; Rindt, C., An Experimentally Validated Numerical Model of Interface Advance of the Lithium Sulfate Monohydrate Dehydration Reaction. J. Therm. Anal. Calorim. 2016, 124, $1109-1118$.

49. Seto, Y.; Sato, H.; Masuda, Y., Effect of Water Vapor Pressure on Thermal Dehydration of Lithium Sulfate Monohydrate. Thermochim. Acta 2002, 388, 21-25.

50. Topley, B.; Smith, M. L., Function of Water Vapour in the Dissociation of a Salt Hydrate. Nature 1931, 128, 302-

302.

51. Topley, B.; Smith, M. L., 69. Kinetics of salt-hydrate dissociations: $\mathrm{MnC}_{2} \mathrm{O}_{4} \cdot 2 \mathrm{H}_{2} \mathrm{O}=\mathrm{MnC}_{2} \mathrm{O}_{4}+2 \mathrm{H}_{2} \mathrm{O}$. J. Chem . Soc. 1935, 321-324.

52. Volmer, M.; Seydel, G., Über die Entwässerungsgeschwindigkeit des Manganooxalat-Dihydrats. Z. Phys. Chem. 1937, 179A, 153-171.

53. Favergeon, L.; Pijolat, M., Influence of Water Vapor Pressure on the Induction Period during $\mathrm{Li}_{2} \mathrm{SO}_{4} \cdot \mathrm{H}_{2} \mathrm{O} \mathrm{Single}$ Crystals Dehydration. Thermochim. Acta 2011, 521, 155-160.

54. L'Vov, B. V., Mechanism of Thermal Dehydration of $\mathrm{Li}_{2} \mathrm{SO}_{4} \cdot \mathrm{H}_{2} \mathrm{O}$. Thermochim. Acta 1998, 315, $145-157$.

55. L'Vov, B. V., Thermal Decomposition of Solids and Melts; Springer: Dordrecht, 2007; Vol. 7.

56. Liavitskaya, T.; Vyazovkin, S., Discovering the Kinetics of Thermal Decomposition during Continuous Cooling. Phys. Chem. Chem. Phys. 2016, 18, 32021-32030.

57. Liavitskaya, T.; Vyazovkin, S., Delving into the Kinetics of Reversible Thermal Decomposition of Solids Measured on Heating and Cooling. J. Phys. Chem. C 2017, 121, 15392-15401.

58. Koga, N.; Favergeon, L.; Kodani, S., Impact of Atmospheric Water Vapor on the Thermal Decomposition of Calcium Hydroxide: A Universal Kinetic Approach to a Physico-Geometrical Consecutive Reaction in Solid-Gas Systems under Different Partial Pressures of Product Gas. Phys. Chem. Chem. Phys. 2019, 21, 11615-11632.

59. Fukuda, M.; Favergeon, L.; Koga, N., Universal Kinetic Description for Thermal Decomposition of Copper(II) Hydroxide over Different Water Vapor Pressures. J. Phys. Chem. C 2019, 123, 20903-20915.

60. Toft Sorensen, O. T.; Rouquerol, J., Sample Controlled Thermal Analysis; Kluwer: Dordrecht, 2003.

61. Criado, J. M.; Perez-Maqueda, L. A.; Koga, N., Sample Controlled Thermal Analysis (SCTA) as a Promising Tool for Kinetic Characterization of Solid-State Reaction and Controlled Material Synthesis. In Thermal Physics and Thermal Analysis, Šesták, J.; Hubík, P.; Mareš, J. J., Eds. Springer Nature: Switzerland, 2017; pp 11-43.

62. Arii, T.; Kishi, A., The Effect of Humidity on Thermal Process of Zinc Acetate. Thermochim. Acta 2003, 400, $175-185$.

63. Koga, N.; Kimizu, T., Thermal Decomposition of Indium(III) Hydroxide Prepared by the Microwave-Assisted Hydrothermal Method. J. Am. Ceram. Soc. 2008, 91, 4052-4058.

64. Kimura, T.; Koga, N., Thermal Dehydration of Monohydrocalcite: Overall Kinetics and Physico-Geometrical Mechanisms. J. Phys. Chem. A 2011, 115, 10491-10501.

65. Fukuda, M.; Koga, N., Kinetics and Mechanisms of the Thermal Decomposition of Copper(II) Hydroxide: A Consecutive Process Comprising Induction Period, Surface Reaction, and Phase Boundary-Controlled Reaction. J. Phys. Chem. C 2018, 122, 12869-12879.

66. Hansen, L. D.; Eatough, D. J.; Lewis, E. A.; Bergstrom, R. G.; Degraft-Johnson, D.; Cassidy-Thompson, K., Shelf-Life Prediction from Induction Period Calorimetric Measurements on Materials Undergoing Autocatalytic Decomposition. Can. J. Chem. 1990, 68, 2111-2114.

67. Šimon, P., Induction Periods. J. Therm. Anal. Calorim. 2006, 84, 263-270.

68. Kitabayashi, S.; Nakano, M.; Nishikawa, K.; Koga, N., Model Experiment of Thermal Runaway Reactions Using the Aluminum-Hydrochloric Acid Reaction. Journal of Chemical Education 2016, 93, 1261-1266.

69. Garner, W. E., The Kinetics of Endothermic Solid Reactions. In Chemistry of the Solid State, Garrner, W. E., Ed. Butterworths: London, 1955; pp 213-231.

70. Delmon, B., Introduction a la Cinetique Heterogene; Editions Technip: Paris, 1969.

71. Barret, P., Cinetique Heterogene; Gauthier-Villars: Paris, 1973.

72. Tompkins, F. C., Decomposition Reactions. In Treates on Solid State Chemistry, Vol. 4 Reactivity of Solids, Hannay, N. B., Ed. Plenum: New York, 1976; Vol. 4, pp 193-231.

73. Kröger, F. A., The chemistry of Imperfect Crystals: Vol.2, Imperfection Chemistry of Crystalline Solids; NorthHolland Publishing Company: Amsterdam, 1974. 
74. Ingraham, T. R.; Marier, P., Kinetic Studies on the Thermal Decomposition of Calcium Carbonate. Can. J. Chem. Eng. 1963, 41, 170-173.

75. Zawadzki, J.; Bretsznajder, S., Some Remarks on the Mechanism of Reactions of the Type: Solid = Solid + Gas. Trans. Faraday Soc. 1938, 34, 951-959.

76. Benton, A. F.; Drake, L. C., Kinetics of Reaction and Adsorption in the System Silver-Oxygen. J. Am. Chem. Soc. 1934, 56, 255-263.

77. Barret, P., Expression Théorique en Fonction de la Pression de la Loi de Vitesse de Croissance d'une Couche non Protectrice Formée par Décomposition Thermique d'un Solide. C. R. Acad. Sci. Paris, Serie C 1968, $266,856-859$.

78. Searcy, A. W.; Beruto, D., Kinetics of Endothermic Decomposition Reactions. 2. Effects of The Solid and Gaseous Products. J. Phys. Chem. 1978, 82, 163-167.

79. Reading, M.; Dollimore, D.; Whitehead, R., The Measurement of Meaningful Kinetic Parameters for Solid State Decomposition Reactions. J Therm Anal 1991, 37, 2165-2188.

80. Criado, J.; González, M.; Málek, J.; Ortega, A., The Effect of The $\mathrm{CO}_{2}$ Pressure on the Thermal Decomposition Kinetics of Calcium Carbonate. Thermochim. Acta 1995, 254, 121-127.

81. Stanford, V. L.; Liavitskaya, T.; Vyazovkin, S., Effect of Inert Gas Pressure on Reversible Solid-State Decomposition. J. Phys. Chem. C 2019, 123, 21059-21065.

82. Vyazovkin, S., Kinetic Effects of Pressure on Decomposition of Solids. Int. Rev. Phys. Chem. 2020, $39,35-66$.

83. Friedman, H. L., Kinetics of Thermal Degradation of Cha-Forming Plastics from Thermogravimetry, Application to a Phenolic Plastic. J. Polym. Sci., Part C 1964, 6, 183-195.

84. Ozawa, T., Kinetic Analysis of Derivative Curves in Thermal Analysis. J Therm Anal 1970, 2, 301-324.

85. Ozawa, T., Applicability of Friedman Plot. J Therm Anal 1986, 31, 547-551.

86. Málek, J., The Kinetic Analysis of Non-Isothermal Data. Thermochim. Acta 1992, 200, 257-269.

87. Koga, N., Kinetic Analysis of Thermoanalytical Data by Extrapolating to Infinite Temperature. Thermochim. Acta 1995, 258, 145-159.

88. Gotor, F. J.; Criado, J. M.; Málek, J.; Koga, N., Kinetic Analysis of Solid-State Reactions: The Universality of Master Plots for Analyzing Isothermal and Nonisothermal Experiments. J. Phys. Chem. A 2000, 104, 10777-10782.

89. Criado, J. M.; Perez-Maqueda, L. A.; Gotor, F. J.; Málek, J.; Koga, N., A Unified Theory for The Kinetic Analysis of Solid State Reactions under Any Thermal Pathway. J. Therm. Anal. Calorim. 2003, 72, 901-906.

90. Ozawa, T., A New Method of Analyzing Thermogravimetric Data. Bull. Chem. Soc. Jpn. 1965, 38, $1881-1886$.

91. Ozawa, T., Non-Isothermal Kinetics and Generalized Time. Thermochim. Acta 1986, 100, 109-118.

92. Yoshioka, H.; Amita, K.; Hashizume, G., The Nucleation-Two Dimensional Interface Growth Equation for the Thermal Decomposition of $\mathrm{Mg}(\mathrm{OH})_{2}$. Netsu Sokutei 1984, 11, 115-118.

93. Masuda, Y.; Iwata, K.; Ito, R.; Ito, Y., Kinetics of the Thermal Dehydration of Magnesium Oxalate Dihydrate in a Flowing Atmosphere of Dry Nitrogen. J. Phys. Chem. 1987, 91, 6543-6547.

94. Viricelle, J.P. ; Pijolat, M. ; Soustelle, M., Transformation of Cerium(iii) Hydroxycarbonate into Ceria Part 1.-Nucleation and Growth Rates of Ceria. J. Chem. Soc. Faraday Trans, 1995, 91, 4431-4435.

95. Bouineau, V.; Pijolat, M. ; Soustelle, M., Characterisation of the Chemical Reactivity of a $\mathrm{CaCO}_{3}$ Powder for Its Decomposition. J. Europ. Ceram. Soc. 1998, 18, 1319-1324.

96. Kitabayashi, S.; Koga, N., Physico-Geometrical Mechanism and Overall Kinetics of Thermally Induced Oxidative Decomposition of Tin(II) Oxalate in Air: Formation Process of Microstructural Tin(IV) Oxide. J. Phys. Chem. C 2014, 118, 17847-17861.

97. Iwasaki, S.; Kodani, S.; Koga, N., Physico-Geometrical Kinetic Modeling of the Thermal Decomposition of Magnesium Hydroxide. J. Phys. Chem. C 2020, 124, 2458-2471.

98. Ozao, R.; Ochiai, M., Fractal Reaction in Solids - Reaction Functions Reconsidered. J. Ceram. Soc. Jpn. 1993, $101,263-267$.

99. Koga, N.; Tanaka, H., Accommodation of the Actual Solid-State Process in the Kinetic-Model Function .1. Significance of the Nonintegral Kinetic Exponents. J Therm Anal 1994, 41, 455-469.

100. Koga, N.; Málek, J., Accommodation of the Actual Solid-State Process in the Kinetic Model Function. 2. Applicability of the Empirical Kinetic Model Function to Diffusion-Controlled Reactions. Thermochim. Acta 1996, 283, 69-80. 